\title{
Avaliação dos parâmetros de autoadensabilidade e de reologia do concreto autoadensável
}

\author{
Evaluation of the workability and rheology parameters \\ of self-compacting concrete
}

\author{
Marcus Mendes ${ }^{1}$, Elton Bauer ${ }^{2}$, \\ Francisco Silva ${ }^{3}$
}

\author{
${ }^{1}$ Professor efetivo do Instituto Federal de Goiás/Câmpus Formosa-Go e doutorando em Estruturas e Construção Civil da \\ Universidade de Brasília, Brasília, DF \\ e-mail: mvasmendes.ifg@gmail.com \\ ${ }^{2}$ Professor do Departamento de Engenharia Civil e Ambiental da Universidade de Brasília, , Brasília, Brasil. \\ e-mail: elbauerlem@gmail.com \\ ${ }^{3}$ Professor do Departamento de Construção e Estruturas da Universidade Federal da Bahia, Salvador, Bahia, Brasil. \\ e-mail: fgabriel.ufba@gmail.com
}

\begin{abstract}
RESUMO
O concreto autoadensável é de complexa obtenção, por isso exige-se um estudo minucioso da mistura e do seu comportamento no estado fresco. De acordo com os requisitos de autoadensabilidade exigidos pela norma brasileira ABNT NBR 15823-1, decidiu-se obter parâmetros de autoadensabilidade e de reologia por meio de estudos em argamassas e, posteriormente, estudos em concretos. Os parâmetros decorrentes da avaliação das argamassas foram obtidos por meio dos seguintes ensaios: mini-slump, mini-funil e caracterização reológica por meio do reômetro da marca Rheotest N4.1. Os parâmetros provenientes da avaliação dos concretos foram obtidos por meio dos ensaios e modelos matemáticos: slump flow, T500, funil V, anel J, caixa L, caixa U, tubo de segregação, parâmetros reológicos estimados por meio de equações matemáticas propostas por Sedran e De Larrard. Com esses parâmetros, foi possível parametrizar ou mapear os concretos autoadensáveis com vistas na norma NBR 15823, bem como foi feita uma avaliação do emprego da classificação dessa norma para o concreto autoadensável. Constatou-se, por exemplo, que o ensaio T500 não apresentou resultados consistentes de viscosidade plástica aparente quando comparados com os resultados do ensaio de Funil $\mathrm{V}$ para esta mesma característica. Verificou-se que os ensaios que avaliam habilidade passante, tais como, caixa $\mathrm{L}$ e anel $\mathrm{J}$ não demonstraram uma boa relação entre seus resultados, assim podendo comprometer a classificação do concreto como autoadensável. Por fim, de maneira geral, observou-se uma importante relação dos parâmetros de autoadensabilidade e de reologia de argamassas e de concretos e, além disso, despertou-se no sentido de melhor avaliar a autoadensabilidade do concreto diante de algumas inconsistências nos resultados de alguns ensaios.
\end{abstract}

Palavras-chave: concreto autoadensável, argamassa, habilidade passante, capacidade passante, resistência à segregação.

\section{ABSTRACT}

The design of self-compacting concrete is complex, so it requires a thorough study of the mixture and their behavior in the fresh state. According to workability requirements required by the Brazilian standard NBR 15823-1, we decided to get workability parameters and rheology through studies in mortars, and later studies in concrete. The parameters resulting from the evaluation of the mortars were obtained by means of the following tests: mini-slump, mini funnel and rheological characterization using the rheometer of Rheotest N4.1 brand. The parameters resulting from the evaluation of concrete were obtained through the tests and mathematical models: slump flow, T500, V funnel, J ring, L box, U box, segregation tube, rheological parameters estimated by mathematical equations proposed by Sedran and De Larrard. From these parameters, it was possible to parameterize or map the self-compacting concrete according NBR 15823-1, and an assessment was made of the use of this classification standard for self-compacting concrete. It was found, for example, that the T500 test results showed no apparent consistent plastic viscosity compared to plastic apparent viscosity 
results obtained by testing funnel V. It was found that the bolt assays that evaluate the ability such, as box L and $\mathrm{J}$ ring, did not show a good match between their results, so may compromise the classification as selfcompacting concrete. Finally, in general, an important relation of the workability parameters and rheology of mortars and concretes was observed and, in addition, it was awakened in order to better evaluate the workability of the concrete in the face of some inconsistencies in the results of some tests.

Keywords: self compacting concrete, mortar, passing ability, passing ability and segregation resistance..

\section{INTRODUÇÃO}

É sabido que os primeiros estudos sobre concreto autoadensável (CAA) foram coordenados por Hajime Okamura, por volta de 1983, no Japão [1]. Esse concreto possui vantagens exclusivas, cabe destacar alguns exemplos como: redução da mão-de-obra e de equipamentos necessários para o lançamento do concreto, adensamento mais eficiente, redução do prazo de execução devido a alta produtividade e melhor acabamento superficial das peças de concreto. Congressos e conferências para tratar desse tipo de concreto são cada vez mais frequentes como, Five North American [2-4], Seven RILEM conferences [5-7] e o BAC 2015 [8]. Entretanto, o CAA é de difícil obtenção por demandar um estudo complexo na composição e nas proporções de seus materiais, tais como, teor de finos, fração de argamassa, fração de agregados graúdos e teor de superplastificante. Esse estudo é necessário para que o concreto atenda aos requisitos de autoadensabilidade (habilidade passante, capacidade de preenchimento e resistência de segregação) tornando sua obtenção mais simples e viável.

Para produção de concreto autoadensável, o tecnologista do concreto ou pesquisador adota um método de dosagem que mais convém. Uns pesquisadores buscam um método que seja capaz de alcançar os requisitos de autoadensabilidade do concreto de maneira mais rápida e fácil e outros adotam um método que não se preocupa somente com requisitos de autoadensabilidade, mas também com requisitos de propriedades mecânicas, durabilidade e custo benefício. Por meio de parâmetros de autoadensabilidade, de reologia, de propriedades mecânicas e estatísticos é possível construir um método de dosagem [9]. Nesse sentido, SHI et al. [9] definiu-se que os métodos de dosagem voltados para o concreto autoadensável estão inseridos em cinco grupos: métodos de dosagem empírico [10-13];.métodos que levam em consideração a resistência à compressão [14,15]; métodos que levam em consideração a densidade de empacotamento dos agregados [16-22]; métodos que consideram o planejamento fatorial [23-25]; métodos que consideram a reologia da pasta [26-28].

De maneira geral, esses métodos de dosagem partem de estudos em argamassas. Estudos em argamassas são importantes para prever o comportamento do concreto autoadensável no que tange as caraterísticas reológicas e de autoadensabilidade, bem como a possibilidade de efetuar várias combinações com maior número de variáveis, assim contribuindo para o entendimento mais consistente das propriedades estudadas com menor gasto de materiais e de recurso - humano [9]. Isso é possível pelo fato desses materiais cimentícios possuírem comportamentos semelhantes no estado fresco [29].

Diante do exposto, nota-se que há uma preocupação em tornar mais simples a obtenção do concreto autoadensável por meio de estudos em argamassas e variados tipos de metodologia de dosagem. As metodologias de dosagem tomam como premissa referências de valores de parâmetros de autoadensabilidade e de reologia para facilitar o alcance de um concreto que cumpra com os quesitos de autoadensabilidade. Com esse viés, decidiu-se confrontar os parâmetros obtidos de autoadensabilidade e de reologia das argamassas e dos concretos, com intuito principal de facilitar o alcance de concretos autoadensáveis com vistas nas classificações definidas pela ABNT NBR 15823-1 [30].

\section{ASPECTOS RELEVANTES DE AUTOADENSABILIDADE E DE REOLOGIA DE ARGAMASSAS E CONCRETOS}

Como se sabe o estudo em argamassas para previsão da autoadensabilidade de concretos é importante e tem sido adotado na maioria dos métodos de dosagem devido a maior concordância dos seus resultados no estado fresco com os resultados de autoadensabilidade dos concretos [29].

Para tanto, ensaios em argamassas com mini-slump e mini-funil têm sido efetuados para desenvolver traços de CAA. Com esses ensaios se obtêm parâmetros de autoadensabilidade como o valor médio de espalhamento e o tempo de fluidez, além disso, é possível obter parâmetros como a área relativa de espalhamento (Gc) e a velocidade relativa de fluidez (Rc) [1]. Estes últimos parâmetros estão apresentados nas Equações 01 e 02 , respectivamente, em que Dm é o diâmetro de espalhamento médio em mm, D0 é o diâmetro da base do cone em mm e t é o tempo em segundos para argamassa fluir através do funil $\mathrm{V}$. 


$$
\begin{aligned}
& G c=\left(\frac{D m}{D_{0}}\right)^{2}-1 \\
& R_{c}=\frac{10}{t}
\end{aligned}
$$

Esses parâmetros são capazes de avaliar o comportamento das argamassas sob a influência de diferentes aditivos, cimentos e adições minerais [31-35]. LIU [34] lista as razões que esses ensaios são amplamente utilizados para avaliar a autoadensabilidade das argamassas:

- Os dois tipos de ensaios têm uma boa relação com os principais parâmetros reológicos: boas correlações têm sido encontradas entre os resultados de espalhamento e tensão de escoamento, e entre os resultados de funil $\mathrm{V}$ e viscosidade plástica de argamassas ensaiadas;

- As correlações supracitadas estão de acordo com os resultados obtidos por JIN e DOMONE [36], ROY e ROUSSEL [37], SCHWARTZENTRUBER et al. [38] e FUNG [35];

- Os resultados de mini-slump e mini-funil também possuem boas correlações com resultados de ensaios que avaliam a capacidade de preenchimento do CAA. Isto pode ser visto no trabalho de LIU [34];

- Os ensaios em argamassas são simples e eficientes, de tal forma, que necessitam de menor número de pontos experimentais e são mais fáceis de serem operados quando comparados com ensaios em concretos.

A seguir, na Figura1, estão apresentados os aparatos de ensaios mini-slump e mini-funil V [1].

(a)

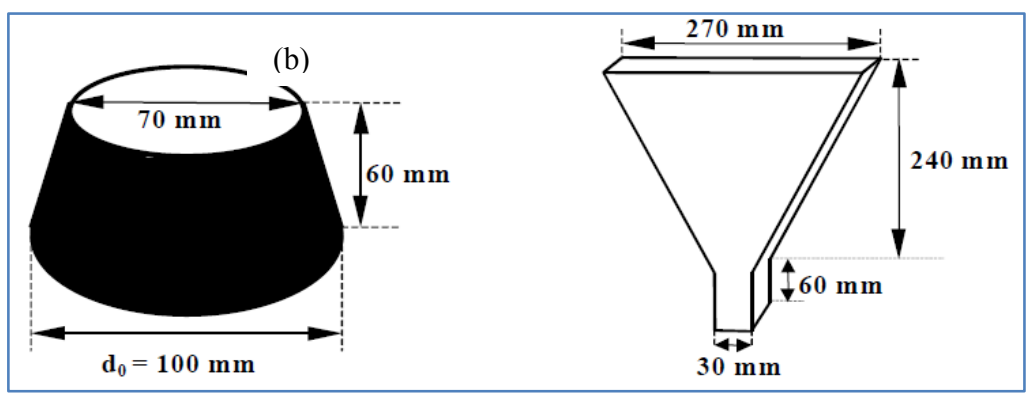

Figura 1: Aparatos de ensaio para avaliar autoadensabilidade em pastas ou argamassas. (a) mini-slump. (b) mini-funil [1].

Para avaliar a autoadensabilidade do concreto, vários métodos de ensaio têm sido propostos e boa parte deles já são normalizados. Ainda não há um consenso geral sobre estes métodos no que tange a sua confiabilidade e eficácia, sendo, portanto, uma questão para ser explorada [39]. A maioria dos métodos de ensaio é usada para avaliar a habilidade passante do CAA. Dentre os ensaios comumente utilizados para esta finalidade são: método do Anel J (J-ring), método da Caixa L e método da Caixa U [40-43]. Outro ensaio comum é o ensaio de slump-flow, o qual determina o espalhamento do concreto e, com isso, avalia-se a capacidade do concreto preencher as fôrmas como, também, é possível se obter a viscosidade aparente por meio da mensuração do tempo do concreto alcançar o espalhamento de $500 \mathrm{~mm}$, conforme está prescrito na norma ABNT NBR 15823-2 [44].

Com relação a resistência a segregação, é possível avaliar de forma qualitativa e quantitativa. Qualitativa é por inspeção visual após o ensaio de espalhamento do concreto, que consiste em verificar a existência de anel de exsudação e uma maior concentração de agregado graúdo na região central do concreto espalhado [43]. De forma quantitativa, pode-se citar os ensaios de coluna de segregação [45], settlement column [46], penetration apparatus [47], segregation probe [48], flow trough [49] e sieve stability [43]. CUSSIGH [50] afirma que o ensaio de coluna de segregação é o mais adequado para se notar diferenças entre diferentes misturas de CAA o que é corroborado pelo grande uso desse ensaio em várias normas internacionais.

A seguir, na Tabela 1, são citadas as normas que prescrevem os ensaios que avaliam autoadensabilidade do concreto no Brasil, na Europa e nos Estados Unidos, as quais são bem semelhantes nas prescrições pelo fato de terem seguido documentos de referência sobre CAA como, por exemplo, a EFNARC [43]. Notase que as normas são recentes e datadas a partir do ano de 2010. 
Tabela 1: Lista dos principais ensaios que avaliam autoadensabilidade do concreto autoadensável com as respectivas normas que os prescrevem no Brasil, Europa e E.U.A.

\begin{tabular}{|c|c|c|c|}
\hline Ensaios & Propriedade Avaliada & & Normas \\
\hline \multirow[t]{3}{*}{ Slump flow } & \multirow{3}{*}{$\begin{array}{l}\text { Habilidade de Preenchimento } \\
\text { Resistência a Segregação por } \\
\text { inspeção visual }\end{array}$} & BRASIL & ABNT NBR 15823-2 (2010) \\
\hline & & EUROPA & EN 12350-8 (2010) \\
\hline & & E.U.A & ASTM C1611 (2009) \\
\hline \multirow[t]{3}{*}{ Slump flow T500 } & \multirow{3}{*}{$\begin{array}{l}\text { Habilidade de Preenchimento } \\
\text { Viscosidade aparente (fuidez) }\end{array}$} & BRASIL & ABNT NBR 15823-2 (2010) \\
\hline & & EUROPA & EN 12350-8 (2010) \\
\hline & & E.U.A & ASTM C1611 (2009) \\
\hline \multirow[t]{3}{*}{ Funil V } & \multirow[t]{3}{*}{ Viscosidade aparente (fuidez) } & BRASIL & ABNT NBR 15823-5 (2010) \\
\hline & & EUROPA & EN 12350-9 (2010) \\
\hline & & E.U.A & ------ \\
\hline \multirow[t]{3}{*}{ Caixa L } & \multirow[t]{3}{*}{ Habilidade Passante } & BRASIL & ABNT NBR 15823-4 (2010) \\
\hline & & EUROPA & EN 12350-10 (2010) \\
\hline & & E.U.A & ------ \\
\hline \multirow[t]{3}{*}{ Caixa $U$} & \multirow[t]{3}{*}{ Habilidade passante } & BRASIL & ------ \\
\hline & & EUROPA & ------ \\
\hline & & E.U.A & ------ \\
\hline \multirow[t]{3}{*}{ Anel J } & \multirow[t]{3}{*}{ Habilidade de Passante } & BRASIL & ABNT NBR 15823-3 (2010) \\
\hline & & EUROPA & EN 12350-12 (2010) \\
\hline & & E.U.A & ASTM C1621 (2009) \\
\hline \multirow[t]{3}{*}{ Coluna Segregação } & \multirow{3}{*}{$\begin{array}{l}\text { Resistência à Segregação } \\
\text { (mensurável) }\end{array}$} & BRASIL & ABNT NBR 15823-6 (2010) \\
\hline & & EUROPA & ------ \\
\hline & & E.U.A & ASTM C1610 (2010) \\
\hline
\end{tabular}

No que se refere aos parâmetros reológicos do concreto autoadensável, há vários estudos no sentido de parametrizar o CAA reologicamente por meio de parâmetros como, tensão de escoamento e viscosidade plástica. Dessa forma, existem estudos que mensuram os parâmetros reológicos por meio de um reômetro para concreto [51-53], outros estudos medem os parâmetros reológicos da argamassa que compõe o concreto [35, $36,55]$ e, por fim, existem modelos matemáticos que estimam os parâmetros reológicos da argamassa e do concreto por meio de parâmetros de autoadensabilidade $[20,56,57]$.

Nesse sentido, a influência de fatores como teor de água, teor de superplastificante e adições minerais frente às propriedades reológicas de pastas, argamassas e concretos podem ser apresentadas em gráficos nomeados como "reografia". A primeira proposta de reografia voltada para CAA mostrou as regiões de valores de tensão de escoamento e viscosidade plástica de um CAA ideal [58]. WALLEVIK e WALLEVIK [58] mostraram uma nova proposta de reografia para CAA, na qual consta um gráfico com diferentes áreas coloridas, sendo que cada área representa um tipo de concreto autoadensável em função dos valores de tensão de escoamento e de viscosidade plástica. Nessa proposta, foi apresentado: CAA ("HY-SCC") com alta tensão de escoamento, CAA ("LV-HY-SCC") com baixa viscosidade plástica e alta tensão de escoamento e CAA ("LV-SCC") com baixa viscosidade plástica. Os concretos autoadensáveis mais recomendados estão numa faixa próxima de tensão de escoamento entre $15 \mathrm{~Pa}$ e $35 \mathrm{~Pa}$ e viscosidade plástica entre $40 \mathrm{~Pa}$.s e $80 \mathrm{~Pa}$.s. A reografia se torna interessante quando se quer conhecer diferentes concretos autoadensáveis a partir de seus comportamentos reológicos, conforme está exemplificado na Figura 13. 
Parâmetros físicos como a densidade de empacotamento, área superficial dos sólidos do sistema de partículas e relação água/sólidos têm sido, também, relacionados com parâmetros reológicos de argamassas e de concretos. Esses parâmetros físicos podem ser representados por um único parâmetro conhecido como WFT (water film thickness), definido como a medida da espessura de filme de água em volta dos grãos sólidos de um sistema granular de um material cimentício. Recentemente, este parâmetro tem sido estudado e defendido como um parâmetro capaz de governar as propriedades reológicas e de trabalhabilidade [35, 59, 60, 61]. KWAN e LI [61] e MENDES e BAUER [62] têm aplicado o parâmetro WFT para argamassas e concretos autoadensáveis.

Com relação aos modelos matemáticos que estimam os parâmetros reológicos por meio de parâmetros de autoadensabilidade, é pertinente frisar os modelos que consideram os resultados de espalhamento (slumpflow), visto que esses são mais comuns e mais consolidados [63]. TANIGAWA et al.[63] constataram que os valores de espalhamento são mais sensíveis para estimar os valores de tensão de escoamento do que valores de viscosidade plástica. SEDRAN e DE LARRARD [19] propuseram equações para estimar os parâmetros reológicos do concreto autoadensavel. Para estimar a tensão de escoamento, tem-se a Equação 3, em que $\tau_{0}$ é a tensão de escoamento $(\mathrm{Pa}), \rho$ é o peso específico do concreto $\left(\mathrm{kg} / \mathrm{m}^{3}\right) ; d_{F}$ é o diâmetro médio final do espalhamento $(\mathrm{mm})$ [19]. Tolera-se um erro médio de $95 \mathrm{~Pa}$ para os valores de tensão de escoamento estimado (teórico).

$$
\begin{aligned}
\tau_{0} & =\frac{\rho}{11740}\left(808-d_{F}\right) \\
\eta & =\frac{\rho}{10000}\left(0,026 d_{F}-2,39\right) T_{500}
\end{aligned}
$$

Para estimar viscosidade plástica, tem-se a Equação 4, em que $\eta$ é a viscosidade plástica (Pa.s); $\rho$ é o peso específico do concreto $\left(\mathrm{kg} / \mathrm{m}^{3}\right) ; d_{F}$ é o diâmetro médio final do espalhamento $(\mathrm{mm}) ; T_{500}$ é o tempo para alcançar um espalhamento de $500 \mathrm{~mm}$.

Portanto, observa-se uma gama de métodos para avaliar autoadensabilidade e reologia de argamassas e de concretos autoadensáveis, bem como métodos de dosagens para se obter o concreto autoadensável. Contudo, observa-se que não há um consenso entre os pesquisadores sobre quais métodos mais adequados para avaliar e conferir autoadensabilidade aos materiais cimentícios [39]. Diante disso, objetivo do presente estudo é a discussão dos critérios de autoadensabilidade associada a avaliação da adequabilidade dos ensaios correntemente empregados.

\section{MATERIAIS E MÉTODOS}

Neste item estão apresentadas as características físicas e químicas dos materiais empregados para produção e os métodos empregados para avaliação das argamassas e concretos frente as propriedades de autoadensabilidade e reologia. Além disso, estão apresentadas as faixas de valores dos parâmetros de autoadensabilidade adotadas neste estudo.

\subsection{Materiais}

Para produção de argamassas e concretos foram empregados materiais finos, areia natural, areia artificial, agregado graúdo britado e superplastificante provenientes da região metropolitana de Brasília, exceto o superplastificante que proveio de uma indústria química do estado de São Paulo. Os finos utilizados foram cimento CPV ARI RS e o fíler calcário calcítico. A areia natural foi a areia rosa de litologia quartzosa e a areia artificial calcária. O agregado graúdo foi brita de diâmetro máximo de $12 \mathrm{~mm}$ de litologia calcária. E o superplastificante utilizado possui base química de policarboxilato de sódio. A seguir, mais detalhes dos materiais empregados.

\subsubsection{Finos}

Os finos empregados foram CPV ARI RS (cimento Portland de alta resistência inicial e resistente à sulfatos) e o fíler calcário. O fíler calcário foi utilizado em substituição, em massa, do cimento até um teor de $30 \%$, com intuito de se alcançar um consumo de cimento próximo de $300 \mathrm{~kg} / \mathrm{m}^{3}$ no concreto. Esse consumo de cimento é definido pela maioria dos produtores de concreto como um consumo viável, com relação ao custo, para produção de concreto autoadensável. A seguir, na Tabela 2, estão apresentadas as principais características físicas e químicas desses finos. 
Tabela 2: Caracterização química e física dos finos: cimento CPV ARI RS, fíler calcário.

\begin{tabular}{l|c|c}
\hline Elemento & Cimento & Fíler calcário \\
\hline $\mathrm{SiO}_{2}$ & 24,58 & 8,62 \\
\hline $\mathrm{CaO}$ & 52,84 & 50,67 \\
\hline $\mathrm{MgO}$ & 3,58 & 3,31 \\
\hline $\mathrm{Al}_{2} \mathrm{O}_{3}$ & 7,43 & 2,89 \\
\hline $\mathrm{Fe}_{2} \mathrm{O}_{3}$ & 3,13 & 1,04 \\
\hline $\mathrm{SO}_{3}$ & 3,23 & --- \\
\hline $\mathrm{K}_{2} \mathrm{O}$ & 0,86 & 0,50 \\
\hline $\mathrm{Na}_{2} \mathrm{O}$ & 0,15 & 0,13 \\
\hline Perda ao fogo & 2,08 & 37,65 \\
\hline Resíduo insolúvel & 8,87 & 13,74 \\
\hline massa específica $\left(\mathrm{g} / \mathrm{cm}^{3}\right)$ & 3,11 & 2,70 \\
\hline Blaine $\left(\mathrm{cm}^{2} / \mathrm{g}\right)$ & 5786 & 3289 \\
\hline
\end{tabular}

Observa-se, na Tabela 2, que o fíler calcário é calcítico. Com relação a finura por meio do ensaio de blaine, nota-se que o cimento possui uma área superficial maior, portanto mais fino que o fíler calcário.

Quanto as distribuições granulométricas dos finos, na Figura 2, verifica-se que a distribuição granulométrica do fíler calcário é levemente superior para as frações entre 0,001 e 0,003; entretanto a distribuição granulométrica do cimento se destaca superior de forma mais acentuada a partir da fração 0,003. Esse comportamento pode contribuir para explicar a maior finura do cimento com relação o fíler calcário.

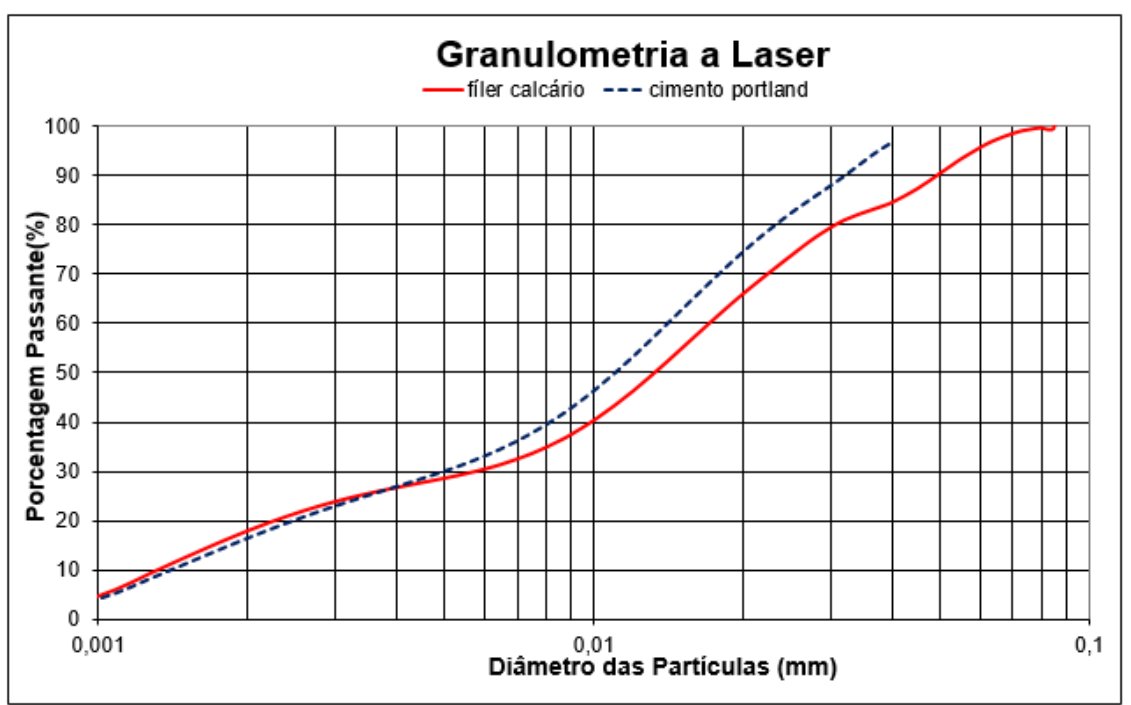

Figura 2: Distribuição granulométrica a laser dos finos.

\subsubsection{Agregados}

Adotou-se a norma NBR NM 248 [64] para determinar a distribuição granulométrica dos agregados. Para determinação da distribuição granulométrica do agregado miúdo foi incluída a peneira de abertura $0,075 \mathrm{~mm}$, com intuito de verificar o teor de finos que é um parâmetro importante no alcance da estabilidade do concreto autoadensável no estado fresco. A seguir, as principais características dos agregados:

- Areia quartzosa (rosa): a sua distribuição granulométrica não se enquadra na zona utilizável, sendo, portanto, uma areia com maior predominância de grãos de diâmetro inferior a $0,3 \mathrm{~mm}$ e seus finos equivalem a 4,3\% da fração total. Informações mais detalhadas sobre a distribuição granulométrica dessa areia, bem como outras características físicas estão apresentadas na Tabela 3;

- Areia artificial calcária: os finos dessa areia correspondem a $0,9 \%$ da fração total. A sua distribuição granulométrica e outras características físicas estão apresentadas na Tabela 3.

- Combinação das areias: a maior massa unitária compactada seca da combinação das areias foi encontrada para uma composição de $30 \%$ de areia rosa (quartzosa) e $70 \%$ de areia artificial. Isso representou uma composição de areia com distribuição granulométrica mais ajustada, conforme está apresentada na Tabela 3 ; 
- Agregado graúdo: a sua distribuição granulométrica está boa parte enquadrada na zona 4,8/12,5, conforme está apresentada na Tabela 4. Características físicas como, módulo de finura, diâmetro máximo e massa específica, também, estão apresentadas na Tabela 4.

Tabela 3: Distribuição granulométrica e as principais características físicas dos agregados miúdos .

\begin{tabular}{|c|c|c|c|c|c|c|c|c|c|c|c|}
\hline \multicolumn{12}{|c|}{ Agregados Miúdos } \\
\hline \multicolumn{12}{|c|}{ Distribuição Granulométrica dos Agregados } \\
\hline & & & \multicolumn{9}{|c|}{ Peneiras $(\mathrm{mm})$} \\
\hline & & & 9,5 & 6,3 & 4,75 & 2,36 & 1,18 & 0,6 & 0,3 & 0,15 & 0,075 \\
\hline \multirow[b]{2}{*}{ Zona utilizável } & \multicolumn{2}{|c|}{ lim. inferior (\%) } & $\mathbf{0}$ & $\mathbf{0}$ & $\mathbf{0}$ & $\mathbf{0}$ & 5 & 15 & 50 & 85 & ---- \\
\hline & \multicolumn{2}{|c|}{$\begin{array}{l}\text { lim. superior } \\
(\%)\end{array}$} & $\mathbf{0}$ & 7 & 10 & 25 & 50 & 70 & 95 & 100 & --- \\
\hline \multirow{2}{*}{ Zona ótima } & \multicolumn{2}{|c|}{ lim. inferior (\%) } & $\mathbf{0}$ & $\mathbf{0}$ & $\mathbf{0}$ & 10 & 20 & 35 & 65 & 90 & ---- \\
\hline & \multicolumn{2}{|c|}{ lim superior (\%) } & $\mathbf{0}$ & $\mathbf{0}$ & 5 & 20 & 30 & 55 & 85 & 95 & ---- \\
\hline $\begin{array}{c}\text { Areia rosa (quar- } \\
\text { tzosa) }\end{array}$ & \multicolumn{2}{|c|}{$\begin{array}{c}\% \text { retida acumu- } \\
\text { lada }\end{array}$} & 0,0 & 0,1 & 0,2 & 0,6 & 1,3 & 2,8 & 10,9 & 92,7 & 95,7 \\
\hline $\begin{array}{c}\text { Areia artificial } \\
\text { calcária }\end{array}$ & \multicolumn{2}{|c|}{$\begin{array}{c}\% \text { retida acumu- } \\
\text { lada }\end{array}$} & 0 & 0,1 & 0,3 & 7,8 & 35,8 & 64,8 & 84,1 & 98,3 & 99,1 \\
\hline Areia combinada & \multicolumn{2}{|c|}{$\begin{array}{l}\% \text { retida acumu- } \\
\text { lada }\end{array}$} & 0,0 & 0,1 & 0,2 & 6,5 & 29,5 & 50,8 & 64,4 & 84,4 & 96,5 \\
\hline \multicolumn{12}{|c|}{ Principais Características Físicas } \\
\hline & & \multicolumn{4}{|c|}{ Massa Específica $\left(\mathbf{g} / \mathrm{cm}^{3}\right)$} & \multicolumn{3}{|c|}{ Diâmetro Máximo (mm) } & \multicolumn{3}{|c|}{ Módulo de Finura } \\
\hline \multicolumn{2}{|c|}{ Areia rosa (quartzosa) } & \multicolumn{4}{|c|}{2,66} & \multicolumn{3}{|c|}{0,60} & \multicolumn{3}{|c|}{1,09} \\
\hline \multicolumn{2}{|c|}{ Areia artificial calcária } & \multicolumn{4}{|c|}{2,73} & \multicolumn{3}{|c|}{4,75} & \multicolumn{3}{|c|}{2,91} \\
\hline
\end{tabular}

Tabela 4: Distribuição granulométrica e as principais características físicas da brita calcária.

\begin{tabular}{|c|c|c|c|c|c|c|c|c|c|c|c|}
\hline & & & & & gado & iraúdo & & & & & \\
\hline \multicolumn{12}{|c|}{ Distribuição Granulométrica } \\
\hline & & & \multicolumn{9}{|c|}{ Peneiras(mm) } \\
\hline & & & 25 & 19 & 12,5 & 9,5 & 6,3 & 4,75 & 2,36 & --- & --- \\
\hline \multirow[b]{2}{*}{ Zona 4,8/12,5 } & & im. inferior (\%) & $\mathbf{0}$ & $\mathbf{0}$ & $\mathbf{0}$ & 2 & 40 & 80 & 95 & --- & --- \\
\hline & & $\begin{array}{l}\text { lim. superior } \\
(\%)\end{array}$ & $\mathbf{0}$ & $\mathbf{0}$ & 5 & 15 & 65 & 100 & 100 & --- & --- \\
\hline Brita calcária & & $\begin{array}{l}\text { \% retida acumu- } \\
\text { lada }\end{array}$ & 0,0 & 0,0 & 1,5 & 17,5 & 49,2 & 66,4 & 94,8 & --- & --- \\
\hline \multicolumn{12}{|c|}{ Principais Características Físicas } \\
\hline \multicolumn{6}{|c|}{ Massa Específica $\left(\mathbf{g} / \mathbf{c m}^{3}\right)$} & \multicolumn{3}{|c|}{ Diâmetro Máximo $(\mathrm{mm})$} & \multicolumn{3}{|c|}{ Módulo de Finura } \\
\hline \multicolumn{3}{|c|}{ Brita calcária } & \multicolumn{3}{|c|}{2,73} & \multicolumn{3}{|c|}{12,50} & \multicolumn{3}{|c|}{5,78} \\
\hline
\end{tabular}

\subsubsection{Aditivo Superplastificante}

Foi feito um estudo em argamassas de relação água/sólidos (em volume) igual a 0,45; a fim de selecionar o aditivo superplastificante a base de policarboxilato de sódio, de um mesmo fabricante, que propiciasse uma autoadensabilidade mais adequada e duradoura de acordo com os propósitos e limites adotados da presente pesquisa. Para essa avaliação, considerou-se os resultados de espalhamento e de fluidez das argamassas diante da adoção das seguintes variáveis independentes: tempo (níveis: 30min, 60min e 90min); tipo de aglomerante (níveis: referência, 20\% de substituição de fíler calcário, 30\% de substituição de fíler calcário); superplastificante (níveis: $\mathrm{spA}$; spB; spC) e teor de aditivo em função do consumo de aglomerante (níveis: 0,6\%, $0,8 \%, 1,0 \%, 1,2 \%, 1,4 \%)$. Dessa forma, constatou-se que o aditivo superplastificante a base de policarboxilato de sódio com maior proporção de resíduo sólido, contribuiu para propiciar uma melhor autoadensabilidade as argamassas. A partir daí, somente esse aditivo foi adotado para produção de argamassas e de concretos do presente estudo. $\mathrm{Na}$ Tabela 5, encontra-se as principais características desse aditivo selecionado. 
Tabela 5: Principais características do aditivo superplastificante empregado nesta pesquisa.

\begin{tabular}{c|c|c}
\hline Características Determinadas & Norma & Resultados \\
\cline { 1 - 1 } $\mathrm{pH}$ & \multirow{2}{*}{ NBR 10908} & 6,00 \\
\cline { 1 - 1 } & & 37,06 \\
\hline Resíduo sólido $(\%)$ & & 1,09 \\
\hline Densidade $\left(\mathrm{g} / \mathrm{cm}^{3}\right)$ & &
\end{tabular}

\subsection{Descrição das etapas do programa experimental}

O programa experimental deste trabalho teve como objetivo principal buscar concretos autoadensáveis definidos conforme a norma ABNT NBR 15823 - 1 [30]. Para isso, o presente estudo dividiu-se em duas etapas. A primeira etapa consistiu em avaliar a autoadensabilidade das argamassas por meio dos ensaios de minislump e de mini-funil e, também, avaliou-se a reologia por meio de parâmetros medidos de tensão de escoamento e de viscosidade plástica. Em seguida, na segunda etapa, foram produzidos concretos com base em proporções de materiais de argamassas tomadas como referência a partir de uma análise feita após o cumprimento da primeira etapa. Nesta segunda etapa, avaliou-se a autoadensabilidade do concreto por meio dos seguintes ensaios: determinação do espalhamento (slump-flow) e do tempo de escoamento (t500) pelo método do cone de Abrams, método do anel J, método da caixa L, método do funil V, método da caixa U, método da coluna de segregação e a caracterização reológica foi considerada valores teóricos de tensão de escoamento e de viscosidade plástica por meio de equações propostas por SEDRAN e DE LARRARD [19].

\subsubsection{Estudos em argamassas}

A seguir, estão apresentadas as condições preliminares de análise das argamassas e o desenvolvimento experimental.

A primeira etapa do estudo consistiu na avaliação das argamassas por meio de ensaios de mini-slump e mini-funil, assim como avaliação da estabilidade (resistência à segregação) da mistura por inspeção visual. Para isso, as argamassas sofreram variação em suas composições com as seguintes variáveis independentes: relação água/sólidos - em volume $(0,40 ; 0,45$ e 0,50$)$, tipo de aglomerante (referência, $20 \%$ de substituição por fíler calcário, $30 \%$ de substituição por fíler calcário), teor de aditivo em função da massa do aglomerante $(0,6 \% ; 0,8 \% ; 1,0 \% ; 1,2 \%, 1,4 \%)$. Somente as argamassas de relação água/sólidos igual a 0,45 sofreram variação em cinco níveis de teor de aditivo, as demais argamassas com relação água/sólidos 0,40 e 0,50 sofreram variação em três níveis. Considerou-se para cada ensaio, três leituras por situação de estudo, ou seja, foi adotado três repetições.

No total foram ensaiadas 33 argamassas, das quais 18 foram selecionadas para servirem como referência no alcance de concretos autoadensáveis. As argamassas selecionadas cumpriram com os seguintes quesitos:

- Considerou-se argamassas com espalhamento entre $230 \mathrm{~mm}$ a $330 \mathrm{~mm}$ e tempo de fluidez de até 10 segundos, conforme os valores encontrados por NEPOMUCENO et al. [54];

- Com relação a estabilidade no estado fresco, considerou-se as argamassas coesas e iminentes para exsudar e segregar, como ilustra a Figura 3.

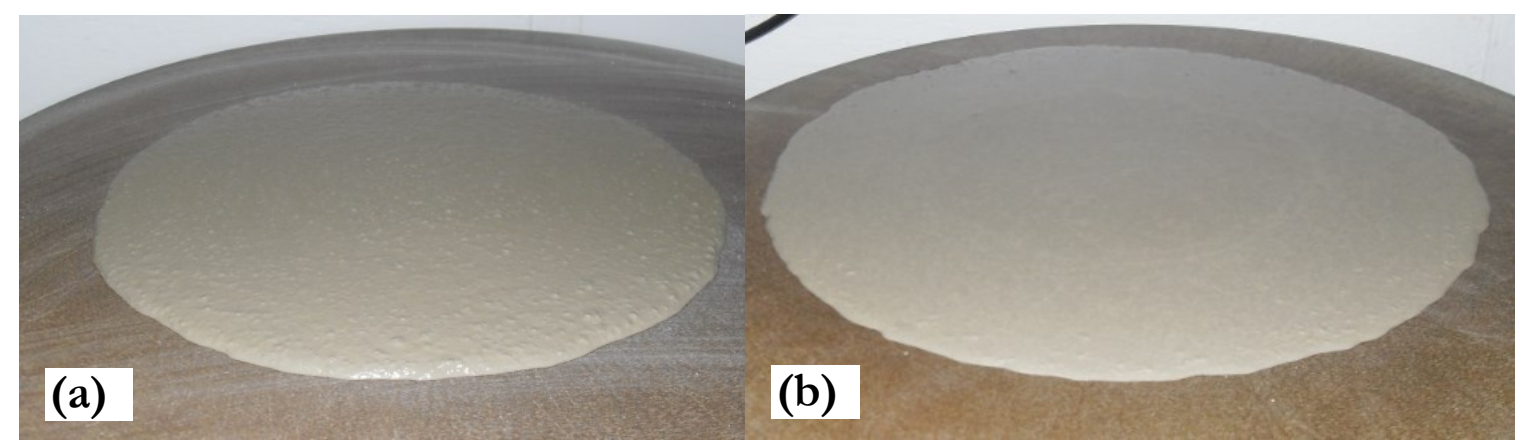

Figura 3: Aparência superficial das argamassas no estado fresco: (a) argamassa coesa; (b) argamassa iminente para exsudar e segregar. 
A seguir, no Quadro 1, consta um esquema que apresenta as argamassas selecionadas para referenciarem os concretos autoadensáveis, as quais estão assinaladas de cor verde. As lacunas de cor vermelha representam as argamassas que não atenderam os requisitos de autoadensabilidade exigidos neste estudo. As lacunas hachuradas de cor cinza representam as argamassas que não foram produzidas.

Quadro 1: Esquema que apresenta as argamassas selecionadas para referenciarem os concretos autoadensáveis.

\begin{tabular}{|c|c|c|c|c|c|c|c|}
\hline \multirow{15}{*}{ 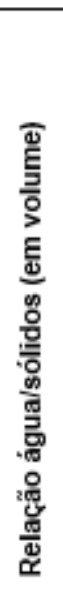 } & \multirow{5}{*}{ ᄋ } & Tipo de aglomerante & \multicolumn{5}{|c|}{ Teor de superplastificante(\%) } \\
\hline & & & 0,6 & 0,8 & 1,0 & 1,2 & 1,4 \\
\hline & & REF & NP & NS & $\mathrm{S}$ & $\mathrm{S}$ & NP \\
\hline & & $20 \%$ subst../filer calcário & NP & NS & $\mathrm{S}$ & $\frac{1}{S}$ & NP \\
\hline & & $30 \%$ subst./filer calcário & NP & NS & $\mathrm{S}$ & $\mathrm{S}$ & $\mathrm{NP}$ \\
\hline & & Tipo de aglomerante & \multicolumn{5}{|c|}{$\frac{1}{\text { Teor de superplastificante }(\%)}$} \\
\hline & \multirow{4}{*}{ 号 } & & 0,6 & 0,8 & 1,0 & 1,2 & 1,4 \\
\hline & & REF & NS & $\mathrm{S}$ & $\mathrm{S}$ & NS & NS \\
\hline & & $20 \%$ subst. / filer calcário & NS & $\mathrm{S}$ & $\mathrm{S}$ & NS & NS \\
\hline & & $30 \%$ subst. /filer calcário & NS & $\mathrm{S}$ & $\mathrm{S}$ & NS & NS \\
\hline & & Tipo de aglomerante & \multicolumn{5}{|c|}{ Teor de superplastificante $(\%)$} \\
\hline & \multirow{4}{*}{ 융 } & & 0,6 & 0,8 & 1,0 & 1,2 & 1,4 \\
\hline & & REF & $\mathrm{S}$ & $\mathrm{S}$ & NS & NP & NP \\
\hline & & $20 \%$ subst. /filer calcário & $\frac{\mathrm{S}}{\mathrm{S}}$ & $\mathrm{S}$ & NS & NP & NP \\
\hline & & $30 \%$ subst. / filer calcário & $\mathrm{S}$ & $\mathrm{S}$ & NS & NP & NP \\
\hline \multicolumn{8}{|c|}{ Legenda: } \\
\hline & & \multicolumn{6}{|c|}{$\begin{array}{l}\text { argamassas não selecionadas (NS); } \\
\text { argamassas selecionadas (S); } \\
\text { situações de estudo que não foram produzidas argamassas (NP). }\end{array}$} \\
\hline
\end{tabular}

Na Tabela 6, está apresentado o quantitativo dos materiais empregados para produção das argamassas supostamente referencias para concreto autoadensável.

Tabela 6: Proporcionamento dos materiais para produção das argamassas referências.

\begin{tabular}{|c|c|c|c|c|c|c|c|c|c|c|}
\hline \multirow[t]{3}{*}{ ARGAMASSA } & \multirow{3}{*}{$\begin{array}{c}\text { Relação á- } \\
\text { gua/sólidos } \\
\text { (em volume) }\end{array}$} & \multicolumn{3}{|c|}{ Aglomerante } & \multirow{3}{*}{\begin{tabular}{|c|} 
Total \\
$\left(\mathrm{kg} / \mathrm{m}^{3}\right)$ \\
\end{tabular}} & \multirow{3}{*}{$\left(\begin{array}{c}a 1^{*} \\
\left(\mathrm{~kg} / \mathrm{m}^{3}\right)\end{array}\right.$} & \multirow{3}{*}{$\begin{array}{c}\mathrm{a2}^{*} \\
\left(\mathrm{~kg} / \mathrm{m}^{3}\right)\end{array}$} & \multirow{3}{*}{$\begin{array}{c}\text { Água } \\
\left(\mathrm{kg} / \mathrm{m}^{3}\right)\end{array}$} & \multicolumn{2}{|c|}{ Aditivo-SP } \\
\hline & & \multirow[t]{2}{*}{$\begin{array}{c}\text { Cimento } \\
\left(\mathrm{kg} / \mathrm{m}^{3}\right)\end{array}$} & \multicolumn{2}{|c|}{ Fíler calcário } & & & & & (\%) & $\left(1 / m^{3}\right)$ \\
\hline & & & Subst. & $\left(\mathrm{kg} / \mathrm{m}^{3}\right)$ & & & & & & \\
\hline $1 \mathrm{~A}$ & 0,40 & 630 & 0 & 0 & 630 & 397 & 926 & 277 & 1,0 & 6,9 \\
\hline $2 \mathrm{~A}$ & 0,40 & 630 & 0 & 0 & 630 & 397 & 926 & 277 & 1,2 & 8,2 \\
\hline $3 \mathrm{~A}$ & 0,40 & 504 & $20 \%$ & 126 & 630 & 397 & 926 & 277 & 1,0 & 6,9 \\
\hline $4 \mathrm{~A}$ & 0,40 & 504 & $20 \%$ & 126 & 630 & 397 & 926 & 277 & 1,2 & 8,2 \\
\hline $5 \mathrm{~A}$ & 0,40 & 441 & $30 \%$ & 189 & 630 & 397 & 926 & 277 & 1,0 & 6,9 \\
\hline $6 \mathrm{~A}$ & 0,40 & 441 & $30 \%$ & 189 & 630 & 397 & 926 & 277 & 1,2 & 8,2 \\
\hline $7 \mathrm{~A}$ & 0,45 & 606 & 0 & 0 & 606 & 382 & 891 & 303 & 0,8 & 5,3 \\
\hline $8 \mathrm{~A}$ & 0,45 & 606 & 0 & 0 & 606 & 382 & 891 & 303 & 1,0 & 6,6 \\
\hline $9 \mathrm{~A}$ & 0,45 & 485 & $20 \%$ & 121 & 606 & 382 & 891 & 303 & 0,8 & 5,3 \\
\hline $10 \mathrm{~A}$ & 0,45 & 485 & $20 \%$ & 121 & 606 & 382 & 891 & 303 & 1,0 & 6,6 \\
\hline $11 \mathrm{~A}$ & 0,45 & 424 & $30 \%$ & 182 & 606 & 382 & 891 & 303 & 0,8 & 5,3 \\
\hline $12 \mathrm{~A}$ & 0,45 & 424 & $30 \%$ & 182 & 606 & 382 & 891 & 303 & 1,0 & 6,6 \\
\hline $13 \mathrm{~A}$ & 0,50 & 588 & 0 & 0 & 588 & 370 & 864 & 323 & 0,6 & 3,8 \\
\hline $14 \mathrm{~A}$ & 0,50 & 588 & 0 & 0 & 588 & 370 & 864 & 323 & 0,8 & 5,1 \\
\hline $15 \mathrm{~A}$ & 0,50 & 470 & $20 \%$ & 118 & 588 & 370 & 864 & 323 & 0,6 & 3,8 \\
\hline $16 \mathrm{~A}$ & 0,50 & 470 & $20 \%$ & 118 & 588 & 370 & 864 & 323 & 0,8 & 5,1 \\
\hline $17 \mathrm{~A}$ & 0,50 & 412 & $30 \%$ & 176 & 588 & 370 & 864 & 323 & 0,6 & 3,8 \\
\hline $18 \mathrm{~A}$ & 0,50 & 412 & $30 \%$ & 176 & 588 & 370 & 864 & 323 & 0,8 & 5,1 \\
\hline
\end{tabular}

Os parâmetros reológicos das argamassas selecionadas, tais como, tensão de escoamento e viscosidade plástica foram medidos por meio de um reômetro coaxial da marca Rheotest RN 4.1, que consiste em um cilíndrico coaxial que armazena a argamassa, conforme ilustra a Figura 4-a. 
Uma haste compatível ao recipiente cilíndrico coaxial, rotaciona-se imerso na argamassa até uma determinada frequência, conforme apresenta a Figura 4-b. Dessa forma, obtém-se o torque necessário para vencer a resistência viscosa da argamassa. Neste estudo, determinou-se avaliação reológica na argamassa de maneira pontual, no tempo 30min (considerar a partir da adição da água de amassamento). Para tanto, adotou-se um aumento de frequência de 0rpm a 150rpm e, em seguida, um decréscimo de frequência de 150rpm a $1 \mathrm{rpm}$. Os parâmetros reológicos medidos estão apresentados em função de unidade de torque (mN.m).

\section{)}

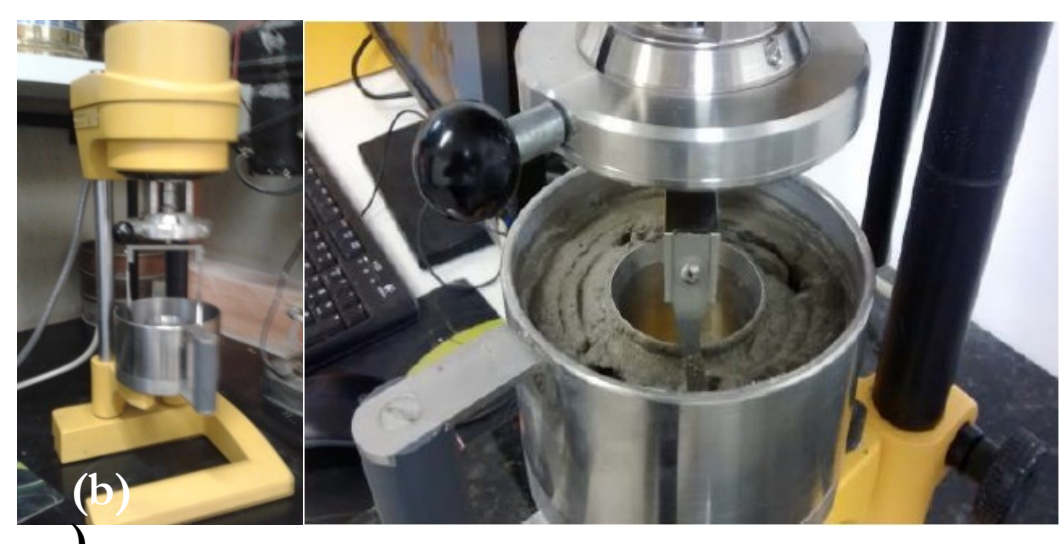

Figura 4: Detalhe do reômetro de argamassas da marca Rheotest N4.1: (a) vista panorâmica do equipamento; (b) vista do recepiente do reômetro.

\subsubsection{Estudos em concretos}

A segunda etapa tratou-se em estudar a autoadensabilidade e a reologia do concreto. Para isso, os concretos foram produzidos a partir das proporções das argamassas referências supracitadas e, também, obedeceram às proporções dos materiais recomendado pelo ACI 237R-07 [65], conforme está apresentado na Tabela 7.

Tabela 7: Proporções recomendadas para dosagem de CAA ACI 237R-07 [65].

\begin{tabular}{l|c}
\hline Volume absoluto de agregado graúdo & $28 \%$ a $32 \%$ \\
\hline Fração de pasta (calculado sobre o volume) & $34 \%$ a $40 \%$ \\
\hline Fração de argamassa(calculado sobre o volume) & $68 \%$ a $72 \%$ \\
\hline Consumo de cimento por $\mathrm{m}^{3}$ & $386 \mathrm{~kg} / \mathrm{m}^{3}$ a $475 \mathrm{~kg} / \mathrm{m}^{3}$ \\
\hline
\end{tabular}

Dessa forma, os concretos tiveram as seguintes proporções dos materiais: consumo médio de aglomerante igual $430 \mathrm{~kg} / \mathrm{m}^{3}$, fração percentual de pasta igual $38 \%$, fração percentual de argamassa igual a $72 \% \mathrm{e}$ percentual de agregado graúdo igual a $29 \%$. Na Tabela 8, está apresentado o quantitativo dos materiais empregados para produção dos concretos. Cabe enfatizar, que a proporção relativa a argamassa do concreto se refere a proporção dos materiais empregados nas argamassas supostas como referências de concretos autoadensáveis. 
Tabela 8: Proporções dos materias dos concretos produzidos neste trabalho.

\begin{tabular}{|c|c|c|c|c|c|c|c|c|c|c|}
\hline \multirow{3}{*}{ CONCRETO } & \multicolumn{4}{|c|}{ Aglomerante } & \multirow{3}{*}{$\begin{array}{c}a 1^{*} \\
\left(\mathrm{~kg} / \mathrm{m}^{3}\right)\end{array}$} & \multirow{3}{*}{$\begin{array}{c}\mathrm{a2}^{*} \\
\left(\mathrm{~kg} / \mathrm{m}^{3}\right)\end{array}$} & \multirow{3}{*}{$\begin{array}{c}\text { Brita - } \\
12 \mathrm{~mm} \\
\left(\mathrm{~kg} / \mathrm{m}^{3}\right)\end{array}$} & \multirow{3}{*}{$\begin{array}{c}\text { Água } \\
\left(\mathrm{kg} / \mathrm{m}^{3}\right)\end{array}$} & \multicolumn{2}{|c|}{ Aditivo SP } \\
\hline & \multirow{2}{*}{$\begin{array}{c}\text { Cimento } \\
\left(\mathrm{kg} / \mathrm{m}^{3}\right)\end{array}$} & \multicolumn{2}{|c|}{$\begin{array}{c}\text { Fíler } \\
\left(\mathrm{kg} / \mathrm{m}^{3}\right)\end{array}$} & \multirow{2}{*}{$\begin{array}{c}\begin{array}{c}\text { Total de } \\
\text { finos }\end{array} \\
\left(\mathrm{kg} / \mathrm{m}^{3}\right) \\
\end{array}$} & & & & & $(\%)$ & litro \\
\hline & & $\%$ & $\left(\mathrm{~kg} / \mathrm{m}^{3}\right)$ & & & & & & & \\
\hline $1 \mathrm{C}$ & 441 & 0 & 0 & 441 & 278 & 648 & 794 & 194 & 1,0 & 4,0 \\
\hline $2 \mathrm{C}$ & 441 & 0 & 0 & 441 & 278 & 648 & 794 & 194 & 1,2 & 4,9 \\
\hline $3 \mathrm{C}$ & 353 & 20 & 88 & 441 & 278 & 648 & 794 & 194 & 1,0 & 4,0 \\
\hline $4 \mathrm{C}$ & 353 & 20 & 88 & 441 & 278 & 648 & 794 & 194 & 1,2 & 4,9 \\
\hline $5 \mathrm{C}$ & 309 & 30 & 132 & 441 & 278 & 648 & 794 & 194 & 1,0 & 4,0 \\
\hline $6 \mathrm{C}$ & 309 & 30 & 132 & 441 & 278 & 648 & 794 & 194 & 1,2 & 4,9 \\
\hline $7 \mathrm{C}$ & 429 & 0 & 0 & 429 & 270 & 631 & 773 & 215 & 0,8 & 3,1 \\
\hline $8 \mathrm{C}$ & 429 & 0 & 0 & 429 & 270 & 631 & 773 & 215 & 1,0 & 3,9 \\
\hline $9 \mathrm{C}$ & 343 & 20 & 86 & 429 & 270 & 631 & 773 & 215 & 0,8 & 3,1 \\
\hline $10 \mathrm{C}$ & 343 & 20 & 86 & 429 & 270 & 631 & 773 & 215 & 1,0 & 3,9 \\
\hline $11 \mathrm{C}$ & 300 & 30 & 129 & 429 & 270 & 631 & 773 & 215 & 0,8 & 3,1 \\
\hline $12 \mathrm{C}$ & 300 & 30 & 129 & 429 & 270 & 631 & 773 & 215 & 1,0 & 3,9 \\
\hline $13 \mathrm{C}$ & 420 & 0 & 0 & 420 & 265 & 617 & 756 & 231 & 0,6 & 2,3 \\
\hline $14 \mathrm{C}$ & 420 & 0 & 0 & 420 & 265 & 617 & 756 & 231 & 0,8 & 3,1 \\
\hline $15 \mathrm{C}$ & 336 & 20 & 84 & 420 & 265 & 617 & 756 & 231 & 0,6 & 2,3 \\
\hline $16 \mathrm{C}$ & 336 & 20 & 84 & 420 & 265 & 617 & 756 & 231 & 0,8 & 3,1 \\
\hline $17 \mathrm{C}$ & 294 & 30 & 126 & 420 & 265 & 617 & 756 & 231 & 0,6 & 2,3 \\
\hline $18 \mathrm{C}$ & 294 & 30 & 126 & 420 & 265 & 617 & 756 & 231 & 0,8 & 3,1 \\
\hline
\end{tabular}

Esses concretos foram submetidos aos ensaios de autoadensabilidade, tais como, espalhamento (slump flow) e t500, anel J, caixa L, funil V, caixa U e Coluna de Segregação conforme estão apresentados na Figura 5. Estes ensaios seguiram as prescrições da norma ABNT 15823 -1 [30], exceto o ensaio da caixa U que seguiu as prescrições da EFNARC [43].

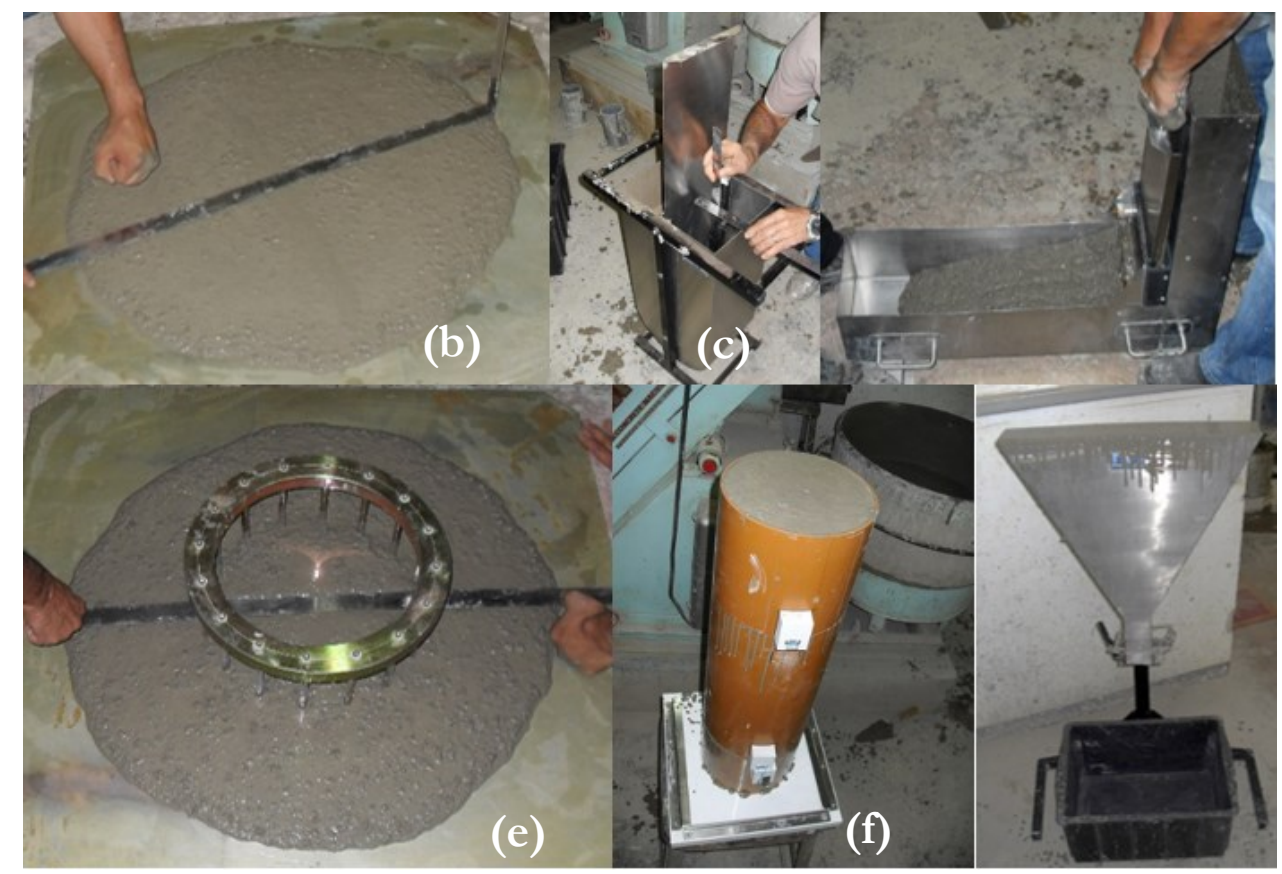

Figura 5: Ensaios que avaliam autoadensabilidade do concreto autoadensável: (a) método do Cone de Abrams - slump flow; (b) método da caixa U; (c) método da caixa L, (d) método do anel J; (e) método da coluna de segregação; (f) método do funil V.

Efetuou-se somente uma leitura por ensaio para cada situação de estudo. Dessa forma, cada situação foi avaliada por um período aproximado de $50 \mathrm{~min}$ pelo fato de envolver vários ensaios. Isso justifica o fato de não considerar mais repetições por ensaio, visto que mais repetições levaria muito tempo que, por sua vez, 
poderia comprometer a avaliação da autoadensabilidade dos concretos. A seguir, na Tabela 9, estão descritas as tolerâncias exigidas pela norma ABNT NBR15823-1 [30] e EFNARC [43] para avaliar autoadensabilidade de concretos.

Tabela 9: Descrição das classes e das tolerâncias dos resultados dos ensaios de autoadensabilidade do concreto, conforme a norma ABNT NBR 15823-1[30] e a EFNARC[43] .

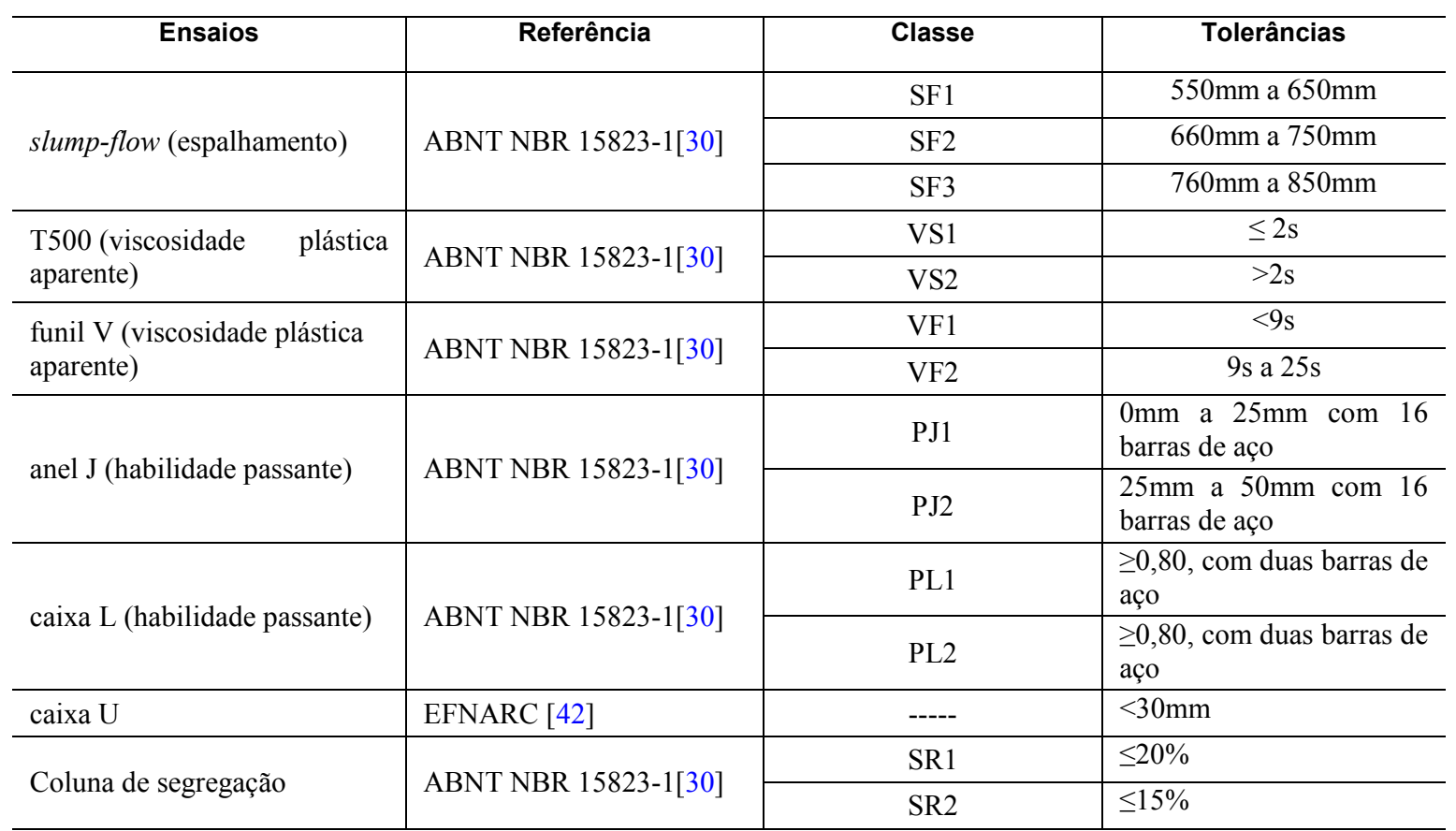

Quanto aos parâmetros reológicos dos concretos, obteve-se os parâmetros de tensão de escoamento e viscosidade plástica por meio de equações matemáticas propostas por SEDRAN e DE LARRARD [19], as quais estão apresentadas nas Equações 3 e 4.

\section{RESULTADOS E DISCUSSÕES}

Neste item, estão apresentados e discutidos os resultados de autoadensabilidade e de reologia dos concretos e das argamassas referências.

\subsection{Autoadensabilidade dos concretos}

Na Tabela 10, estão apresentados os resultados dos ensaios que avaliam autoadensabilidade dos concretos, tais como, slump flow, T500, funil V, anel J, caixa L, caixa U e coluna de segregação, bem como estão classificados os resultados dos ensaios conforme a ABNT NBR 15823-1 [30]. De acordo com a ABNT NBR 15823-1[30], o concreto para ser definido como autoadensável, deve se enquadrar, no mínimo, na classificação prescrita para os ensaios de slump flow, T500 ou funil V, anel J ou caixa L. 
Tabela 10: Resultados e classificações de autoadensabilidade dos concretos.

\begin{tabular}{|c|c|c|c|c|c|c|c|c|c|c|c|c|c|c|c|c|c|c|}
\hline \multirow[t]{2}{*}{ Ensaios } & \multicolumn{18}{|c|}{ CONCRETO } \\
\hline & 1C & $2 \mathrm{C}$ & $3 C$ & $4 \mathrm{C}$ & $5 \mathrm{C}$ & 6C & $7 \mathrm{C}$ & $8 \mathrm{C}$ & $9 \mathrm{C}$ & 10C & $11 \mathrm{C}$ & $12 \mathrm{C}$ & $13 \mathrm{C}$ & $14 C$ & $15 \mathrm{C}$ & $16 \mathrm{C}$ & 17C & $18 \mathrm{C}$ \\
\hline Slump flow $(\mathrm{mm})$ & 525 & 682 & 615 & 716 & 693 & 707 & 580 & 722 & 618 & 720 & 665 & 704 & 520 & 608 & 550 & 682 & 512 & 740 \\
\hline Classe & $\mathrm{N}$ & SF2 & SF1 & SF2 & SF2 & SF2 & SF1 & SF2 & SF1 & SF2 & SF2 & SF2 & $\mathrm{N}$ & SF1 & SF1 & SF2 & $\mathrm{N}$ & SF2 \\
\hline T50 (s) & 4,41 & 5,19 & 4,18 & 3,10 & 4,12 & 2,37 & 2,34 & 3,25 & 2,60 & 3,19 & 2,31 & 1,68 & 2,82 & 3,75 & 1,72 & 1,41 & 2,59 & 1,81 \\
\hline Classe & VS2 & VS2 & VS2 & VS2 & VS2 & VS2 & VS2 & VS2 & VS2 & VS2 & VS2 & VS1 & VS2 & VS2 & VS1 & VS1 & VS2 & VS1 \\
\hline Funil V (s) & 10,78 & 9,25 & 11,47 & 12,34 & 12,16 & 8,04 & 5,91 & 5,25 & 5,91 & 4,40 & 5,56 & 4,69 & 4,09 & 4,53 & 3,66 & 3,31 & 2,88 & 2,84 \\
\hline Classe & VF2 & VF2 & VF2 & VF2 & VF2 & VF1 & VF1 & VF1 & VF1 & VF1 & VF1 & VF1 & VF1 & VF1 & VF1 & VF1 & VF1 & VF1 \\
\hline Anel J (mm) & 68 & 8 & 72 & 38 & 46 & 94 & 50 & 31 & 60 & 86 & 18 & 21 & 60 & 61 & 50 & 65 & 58 & 5 \\
\hline Classe & $\mathrm{N}$ & PJ1 & $\mathrm{N}$ & PJ2 & PJ2 & $\mathrm{N}$ & PJ2 & PJ2 & $\mathrm{N}$ & $\mathrm{N}$ & PJ1 & PJ1 & $\mathrm{N}$ & $\mathrm{N}$ & PJ2 & $\mathrm{N}$ & $\mathrm{N}$ & PJ1 \\
\hline Caixa L & 0,45 & 0,91 & 0,54 & 0,85 & 0,66 & 0,90 & 0,60 & 0,81 & 0,68 & 0,91 & 0,75 & 0,85 & 0,37 & 0,80 & 0,62 & 0,80 & 0,44 & 1,00 \\
\hline Classe & $\mathrm{N}$ & PL2 & $\mathrm{N}$ & PL2 & $\mathrm{N}$ & PL2 & $\mathrm{N}$ & PL2 & $\mathrm{N}$ & PL2 & $\mathrm{N}$ & PL2 & $\mathrm{N}$ & PL2 & $\mathrm{N}$ & PL2 & $\mathrm{N}$ & PL2 \\
\hline Caixa U (mm) & 105 & 10 & 66 & 23 & 34 & 22 & 64 & 9 & 58 & 50 & 35 & 36 & 86 & 48 & 57 & 34 & 97 & 17 \\
\hline Classe & $\mathrm{N}$ & $\mathrm{S}$ & $\mathrm{N}$ & $\mathrm{S}$ & $\mathrm{N}$ & $\mathrm{S}$ & $\mathrm{N}$ & $\mathrm{S}$ & $\mathrm{N}$ & $\mathrm{N}$ & $\mathrm{N}$ & $\mathrm{N}$ & $\mathrm{N}$ & $\mathrm{N}$ & $\mathrm{N}$ & $\mathrm{N}$ & $\mathrm{N}$ & $\mathrm{S}$ \\
\hline Coluna (\%) & 8,17 & 1,84 & 17,80 & 12,10 & 2,82 & 14,60 & 10,25 & 12,63 & 5,86 & 3,56 & 12,36 & 4,08 & 5,53 & 0,40 & 8,27 & 21,71 & 14,34 & 34,26 \\
\hline Classe & SR2 & SR2 & SR1 & SR2 & SR2 & SR2 & SR2 & SR2 & SR2 & SR2 & SR2 & SR2 & SR2 & SR2 & SR2 & $\mathrm{N}$ & SR2 & $\mathrm{N}$ \\
\hline CAA & não & $\operatorname{sim}$ & não & $\operatorname{sim}$ & $\operatorname{sim}$ & $\operatorname{sim}$ & $\operatorname{sim}$ & $\operatorname{sim}$ & não & $\operatorname{sim}$ & $\operatorname{sim}$ & $\operatorname{sim}$ & não & $\operatorname{sim}$ & $\operatorname{sim}$ & $\operatorname{sim}$ & não & $\operatorname{sim}$ \\
\hline
\end{tabular}

Observa-se, na Tabela 10, que treze concretos são classificados como autoadensável de um total de dezoito concretos. Isso significa, que o estudo preliminar em argamassas é importante para buscar referencias de proporções de materiais capazes de alcançarem concretos autoadensáveis. Em uma avaliação mais geral, cabe destacar algumas observações importantes nos resultados dos ensaios que avaliam autoadensabilidade do concreto:

- Observa-se que todos os concretos são classificados frente aos ensaios que avaliam viscosidade aparente, tais como, T500 e Funil V;

- Com relação a avaliação da habilidade passante, nota-se que somente dez concretos são classificados tanto pelo ensaio de anel J como, também, pelo ensaio de caixa L. Isso significa, que não há uma concordância importante entre os ensaios que avaliam habilidade passante;

- O ensaio de caixa U classificou cinco concretos no que se refere o quesito de habilidade passante. Esse ensaio não é prescrito pela norma ABNT NBR 15823-1 [30], portanto necessita-se de mais estudos para propor tolerâncias e classificações de acordo com os concretos brasileiros, a fim de adotá-lo como mais um ensaio para avaliar habilidade passante. É importante ressaltar, que esse ensaio foi considerado importante por LIBRE et al [66] para identificar alterações na mistura do concreto;

- Nota-se que a norma permite classificar um concreto como autoadensável, sem mesmo cumprir com o quesito de resistência à segregação. Isso se comprova na classificação dos concretos $16 \mathrm{C}$ e $18 \mathrm{C}$;

- Observa-se que o quesito habilidade passante, demonstrou-se determinante para classificar o concreto em autoadensável. Pode-se citar o exemplo dos cinco concretos que não foram classificados como autoadensável, dos quais três concretos não cumpriram com o quesito de habilidade passante.

Em uma avaliação mais específica, associou-se os resultados de autoadensabilidade com as características das misturas dos concretos. Dessa forma, tentou-se apontar os prováveis motivos que uns concretos foram classificados como autoadensável e outros não. A Tabela 11, auxilia nessa discussão. 
Tabela 11: Interação dos quesitos atendidos de autoadensabilidade e as caractéristicas das misturas dos concretos, bem como as principais observações constatadas.

\begin{tabular}{|c|c|c|c|c|c|}
\hline \multirow[t]{2}{*}{ Concreto } & \multirow[t]{2}{*}{ CAA $^{*}$} & \multicolumn{3}{|c|}{ Quesitos CAA } & \multirow[t]{2}{*}{ Observações } \\
\hline & & $\mathrm{CP}^{*}$ & $\mathrm{HP}^{*}$ & RS* $^{*}$ & \\
\hline $1 \mathrm{C}$ & & ---- & ---- & $\mathrm{X}$ & teor de SP insuficiente \\
\hline $2 \mathrm{C}$ & $\mathrm{X}$ & $\mathrm{X}$ & $\mathrm{X}$ & $\mathrm{X}$ & teor de SP adequado \\
\hline $3 \mathrm{C}$ & & $\mathrm{X}$ & & $\mathrm{X}$ & teor de SP insuficiente \\
\hline $4 \mathrm{C}$ & $\mathrm{X}$ & $\mathrm{X}$ & $\mathrm{X}$ & $\mathrm{X}$ & teor de SP adequado \\
\hline $5 \mathrm{C}$ & $\mathrm{X}$ & $\mathrm{X}$ & $\mathrm{X}$ & $\mathrm{X}$ & \\
\hline $6 \mathrm{C}$ & $\mathrm{X}$ & $\mathrm{X}$ & $\mathrm{X}$ & $\mathrm{X}$ & $\begin{array}{l}\text { aumento de SP melhorou habilidade passan- } \\
\text { te do concreto }\end{array}$ \\
\hline $7 \mathrm{C}$ & $\mathrm{X}$ & $\mathrm{X}$ & $\mathrm{X}$ & $\mathrm{X}$ & \\
\hline $8 \mathrm{C}$ & $\mathrm{X}$ & $\mathrm{X}$ & $\mathrm{X}$ & $\mathrm{X}$ & \\
\hline $9 \mathrm{C}$ & & $\mathrm{X}$ & & $\mathrm{X}$ & teor de SP insuficiente \\
\hline $10 \mathrm{C}$ & $\mathrm{X}$ & $\mathrm{X}$ & $\mathrm{X}$ & $\mathrm{X}$ & teor de SP adequado \\
\hline $11 \mathrm{C}$ & $\mathrm{X}$ & $\mathrm{X}$ & $\mathrm{X}$ & $\mathrm{X}$ & \\
\hline $12 \mathrm{C}$ & $\bar{X}$ & $\mathrm{X}$ & $\mathrm{X}$ & $\mathrm{X}$ & $\begin{array}{l}\text { aumento de SP melhorou habilidade passan- } \\
\text { te do concreto }\end{array}$ \\
\hline $13 \mathrm{C}$ & & ---- & ---- & $\mathrm{X}$ & teor de SP insuficiente \\
\hline $14 \mathrm{C}$ & $\mathrm{X}$ & $\mathrm{X}$ & $\mathrm{X}$ & $\mathrm{X}$ & teor de SP adequado \\
\hline $15 \mathrm{C}$ & $\mathrm{X}$ & $\mathrm{X}$ & $\mathrm{X}$ & $\mathrm{X}$ & \\
\hline $16 \mathrm{C}$ & $\mathrm{X}$ & $\mathrm{X}$ & $\mathrm{X}$ & ---- & \\
\hline $17 \mathrm{C}$ & & ---- & ---- & $\mathrm{X}$ & teor de SP insuficiente \\
\hline $18 \mathrm{C}$ & $\mathrm{X}$ & $\mathrm{X}$ & $\mathrm{X}$ & $\begin{array}{l}--- \\
\end{array}$ & $\begin{array}{l}\text { aumento de SP comprometeu a estabilidade } \\
\text { do concreto }\end{array}$ \\
\hline \multicolumn{6}{|c|}{$\begin{array}{l}\text { Legenda: } \\
C A A^{*}=\text { classificado como concreto autoadensável } \\
\mathrm{CP}^{*}=\text { capacidade de preenchimento (quando atendido o espalhamento e a viscosidade pelo t500 ou funil V) } \\
\mathrm{HP}^{*}=\text { habilidade passante } \\
\mathrm{RS}^{*}=\text { resistência à segregação }\end{array}$} \\
\hline
\end{tabular}

Nota-se, na Tabela 11, que no geral os concretos com proporções iguais, quanto a quantidade de materiais secos e de água, o aumento no teor de aditivo foi importante para enquadrar o concreto como autoadensável conforme a ABNT NBR 15823-1[30]. Pode-se citar os seguintes exemplos: 1C e 2C, somente o 2C foi classificado como CAA; 3C e 4C, somente o 4C foi classificado como CAA; 9C e 10C, somente o $10 \mathrm{C}$ foi classificado como CAA; 13C e 14C, somente o 14C foi classificado como CAA; 17C e 18C, somente $18 \mathrm{C}$ foi classificado como CAA. Cabe destacar o 18C, que o teor de aditivo empregado foi capaz de atender a autoadensabilidade exigida pela norma, porém comprometeu a estabilidade da mistura. Observa-se, também, que os concretos $1 \mathrm{C}, 3 \mathrm{C}$ e 5C são de mesma relação água/sólidos igual a 0,40 , foram misturados com mesmo teor de aditivo superplastificante, entretanto possuem teor de substituição de fíler calcário $0 \%, 20 \%$ e $30 \%$, respectivamente. Ciente disso, o concreto $5 \mathrm{C}$ foi definido como autoadensável devido ao fato de possuir $30 \%$ de fíler calcário em substituição ao cimento, pode-se dizer que nesse caso o fíler calcário foi importante para que esse concreto atendesse os quesitos de autoadensabilidade corroborando com as constatações observadas por SAHMARAN et al. [67] e TÜRKEL e KANDEMIR [68].

\subsubsection{Relação entre os comportamentos observados de autoadensabilidade}

A seguir, estão apresentadas as relações entre os, a saber: slump flow, funil V, T500, caixa L e caixa U. Para tanto, adotou-se uma padronização em todos os gráficos para facilitar a discussão dos resultados. Essa padronização consiste em apresentar os resultados dos concretos e das argamassas autoadensáveis com pontos verdes, enquanto os resultados dos concretos e das argamassas não autoadensáveis (concreto convencional CCV) são apresentados com pontos de cor vermelha. É importante frisar, que o concreto classificado como autoadensável, a argamassa que o referenciou também foi considerada como autoadensável.

Na Figura 6, tem-se a relação dos resultados dos ensaios de Funil V e T500. Ambos resultam em valores de viscosidade plástica aparente de acordo com a norma ABNT NBR 15823-1[30]. Esta norma permite que seja considerado um dos ensaios para avaliar viscosidade plástica aparente. Observa-se, na Figura 6, que a relação dos resultados destes ensaios foi definida por uma regressão linear com coeficiente de determinação igual a 0,46. Diante disso, constata-se que a relação não é boa, portanto sugere-se um cuidado maior na avaliação desse quesito para a avaliação da autoadensabilidade do concreto. 


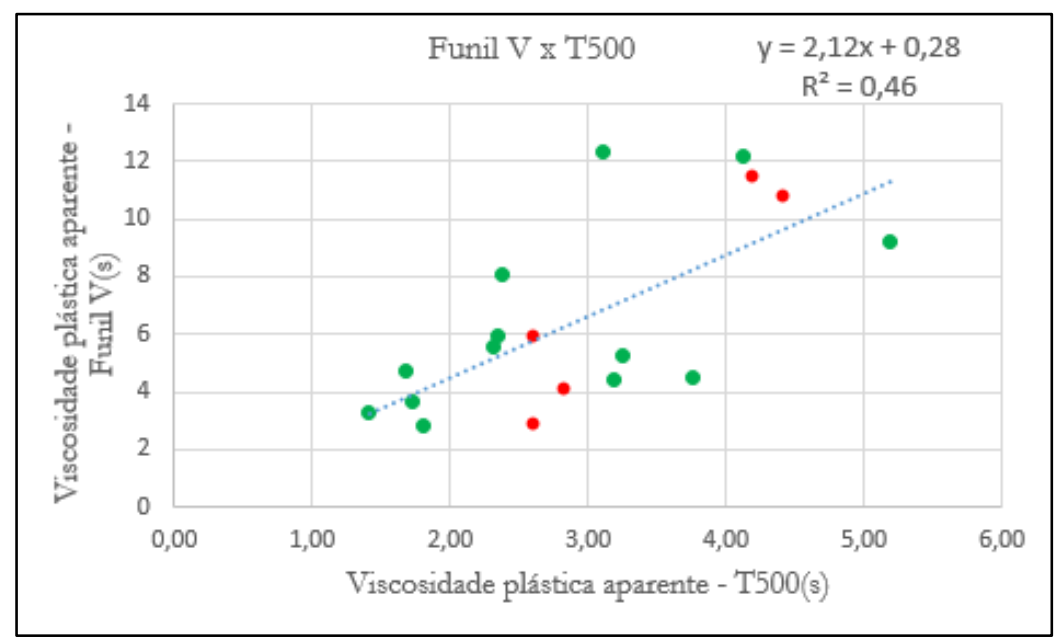

Figura 6: Regressão tipo linear entre os resultados de viscosidade plástica aparente dos concretos obtidos tanto pelo ensaio de Funil V como também pelo ensaio de T500.

Ensaios que avaliam habilidade passante, tais como, caixa L e caixa $U$ apresentaram uma relação importante com o ensaio de slump-flow neste trabalho. Primeiro, tem-se na Figura 7(a), uma regressão linear dos resultados da caixa L e de slump-flow, na qual consta uma equação com coeficiente de determinação igual a 0,80 . Nota-se, também, que os concretos classificados como autoadensável apresentaram resultados entre os valores de 0,6 e 1,0. Diante disso, os concretos que apresentaram valores abaixo de 0,8 contrariaram a tolerância permitida para o ensaio de caixa L, no entanto esses concretos foram aprovados no quesito habilidade passante por meio da tolerância prescrita para o ensaio de anel J. Essa adversidade nos resultados desperta a importância de rever as tolerâncias para o quesito de habilidade passante desses ensaios, bem como desperta a possibilidade de exigir os dois ensaios para avaliar esse quesito de autoadensabilidade ou adoção de somente um ensaio. Essa questão torna-se mais importante para apreciação quando se considera que o anel $\mathrm{J}$ brasileiro pode conferir um menor rigor na avaliação da habilidade passante do concreto, visto que esse anel possui barras verticais com diâmetros iguais a $(10 \pm 3,0) \mathrm{mm}$, portanto esta medida de diâmetro é inferior dos anéis $J$ empregados por normas europeias e pela norma dos Estados Unidos que são iguais $(18 \pm 0,5) \mathrm{mm}$ e $(16 \pm 3,3) \mathrm{mm}$, respectivamente.

Quanto a relação dos resultados dos ensaios de caixa U e slump-flow, verifica-se, também, uma regressão linear conforme está apresentado na Figura 7(b). Na qual consta uma equação com coeficiente de determinação igual ao encontrado na relação caixa $\mathrm{L}$ e slump-flow que foi 0,80 . Isso demonstra e reforça que o ensaio de slump-flow pode ser uma alternativa para prever habilidade passante do concreto.

Nota-se, na Figura 8(b), que para concretos autodensáveis com valores de espalhamento entre $650 \mathrm{~mm}$ e $750 \mathrm{~mm}$ seus resultados no ensaio de caixa $\mathrm{U}$ situaram-se no intervalo entre $0 \mathrm{~mm}$ e $50 \mathrm{~mm}$. No geral, os concretos classificados como autoadensável, apresentaram resultados no ensaio de caixa $\mathrm{U}$ no intervalo de 0 $\mathrm{mm}$ a $60 \mathrm{~mm}$. Portanto, de acordo presente estudo sugere-se dois níveis de classificação de autoadensabilidade, sendo um nível de resultados entre $0 \mathrm{~mm}$ e $30 \mathrm{~mm}$ e outro nível entre $30 \mathrm{~mm}$ e $60 \mathrm{~mm}$, visto que esse ensaio não é normalizado e a tolerância de resultado mais difundida pelo meio técnico é o valor limite de $30 \mathrm{~mm}$, como visto na Tabela 8. Cabe destacar, que Libre et al. [66] consideraram o ensaio de caixa U mais capaz do que o ensaio da caixa L para identificar alterações na composição do concreto quando envolve o emprego de adições minerais e aditivos químicos, o que reforça uma futura inclusão desse ensaio em normas vigentes. 


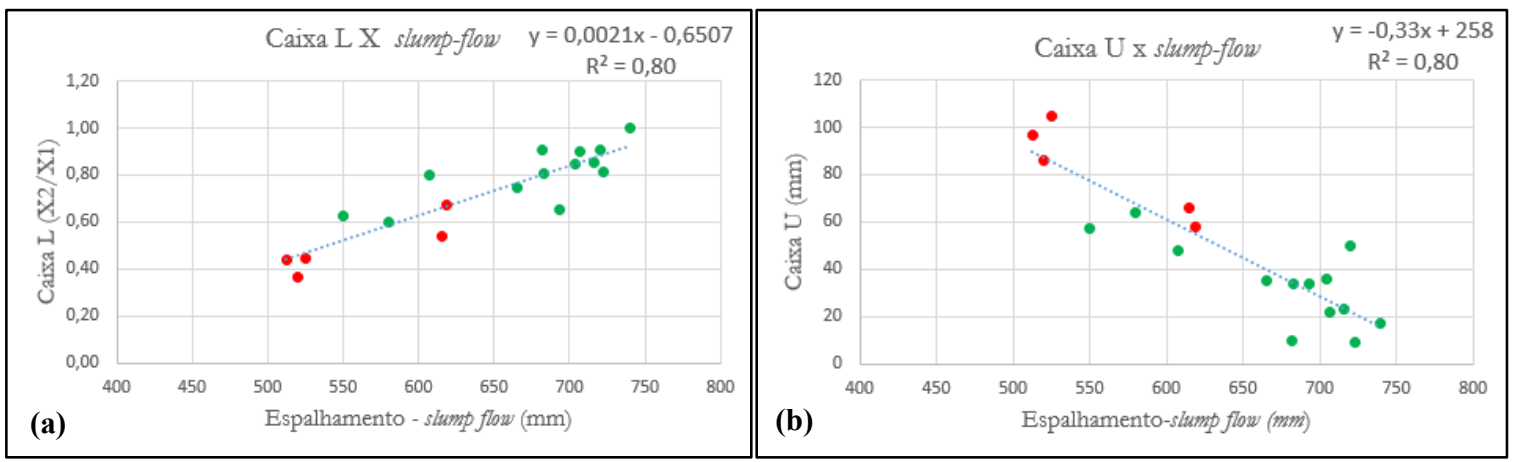

Figura 7: (a) Regressão tipo linear entre os resultados de espalhamento e do ensaio de caixa L dos concretos.(b) Regressão tipo linear entre os resultados de espalhamento e do ensaio de caixa $U$ dos concretos.

Quanto a estabilidade do concreto, observou-se que os concretos $16 \mathrm{C}$ e $18 \mathrm{C}$ apresentaram resultados iguais a $21,31 \%$ e $34,26 \%$, respectivamente. Isso significa, que esses concretos segregaram conforme definido pela ABNT NBR 15823-1 [30]. Entretanto, quando se faz uma avaliação por inspeção visual do estado fresco desses concretos, nota-se na Figura 8 (a), que o concreto 16C é um concreto coeso, ao contrário, do concreto 18C, Figura 8 (b), que apresenta ser um concreto que realmente segregou e exsudou. Diante disso, constata-se que a inspeção visual ainda é um instrumento importante para avaliar a estabilidade de qualquer material cimentício no estado fresco, assim como desperta-se o questionamento frente o ensaio de coluna de segregação no que tange sua capacidade de classificar a estabilidade do concreto.

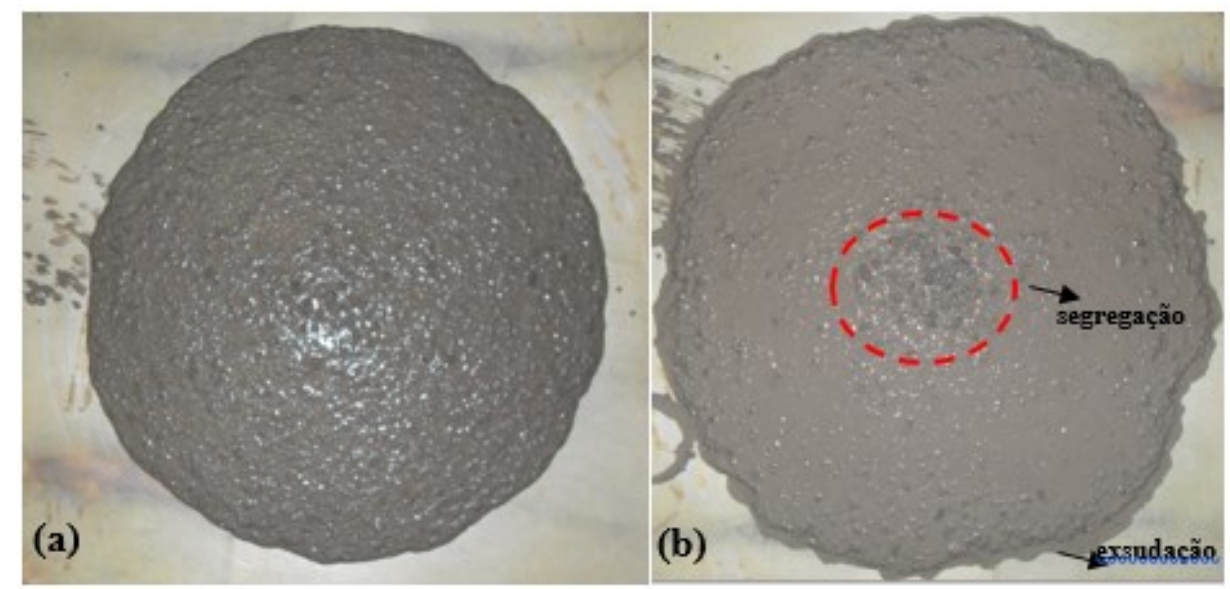

Figura 8: Aparência superficial dos concretos: (a) 16C; (b) 18C.

\subsection{Autoadensabilidade das argamassas dos concretos}

Na Tabela 12, estão apresentados os resultados de autoadensabilidade obtidos pelos ensaios de mini-slump e de mini-funil. 
Tabela 12: Resultados de autoadensabilidade das argamassas referências por meio dos ensaios de mini-slump e minifunil V.

\begin{tabular}{|c|c|c|c|c|c|}
\hline \multirow{3}{*}{$\begin{array}{l}\text { ARGAMASSA } \\
\text { Referência }\end{array}$} & \multirow[t]{3}{*}{ AAA $^{*}$} & \multicolumn{4}{|c|}{$\begin{array}{l}\text { Avaliação da autoadensabilidade } \\
\end{array}$} \\
\hline & & \multicolumn{2}{|c|}{ mini-slump (mm) } & \multicolumn{2}{|c|}{ (mini-funil) (s) } \\
\hline & & Espalhamento (mm) & $\begin{array}{l}\text { Capacidade de Defor- } \\
\text { mação (Gc) }\end{array}$ & $\begin{array}{l}\text { Tempo de flui- } \\
\text { dez (s) }\end{array}$ & $\begin{array}{c}\text { Velocidade de } \\
\text { deformação - } \\
\operatorname{Rm}\left(\mathrm{s}^{-1}\right)\end{array}$ \\
\hline $1 \mathrm{~A}$ & & 235 & 4,52 & 6,71 & 1,49 \\
\hline $2 \mathrm{~A}$ & $\mathrm{X}$ & 308 & 8,49 & 5,46 & 1,83 \\
\hline $3 \mathrm{~A}$ & & 289 & 7,37 & 5,31 & 1,88 \\
\hline $4 \mathrm{~A}$ & $\mathrm{X}$ & 321 & 9,28 & 3,45 & 2,90 \\
\hline $5 \mathrm{~A}$ & $\mathrm{X}$ & 306 & 8,36 & 3,53 & 2,83 \\
\hline $6 \mathrm{~A}$ & $\mathrm{X}$ & 314 & 8,86 & 3,76 & 2,66 \\
\hline $7 \mathrm{~A}$ & $\mathrm{X}$ & 273 & 6,45 & 3,17 & 3,15 \\
\hline $8 \mathrm{~A}$ & $\mathrm{X}$ & 349 & 11,18 & 2,59 & 3,86 \\
\hline $9 \mathrm{~A}$ & & 257 & 5,60 & 3,10 & 3,23 \\
\hline $10 \mathrm{~A}$ & $\mathrm{X}$ & 337 & 10,38 & 2,26 & 4,42 \\
\hline $11 \mathrm{~A}$ & $\mathrm{X}$ & 280 & 6,84 & 2,68 & 3,73 \\
\hline $12 \mathrm{~A}$ & $\mathrm{X}$ & 337 & 10,38 & 2,10 & 4,76 \\
\hline $13 \mathrm{~A}$ & & 237 & 4,63 & 2,51 & 3,98 \\
\hline $14 \mathrm{~A}$ & $\mathrm{X}$ & 322 & 9,39 & 1,99 & 5,03 \\
\hline $15 \mathrm{~A}$ & $\mathrm{X}$ & 248 & 5,13 & 2,04 & 4,90 \\
\hline $16 \mathrm{~A}$ & $\mathrm{X}$ & 331 & 9,98 & 1,65 & 6,07 \\
\hline $17 \mathrm{~A}$ & & 241 & 4,82 & 2,09 & 4,78 \\
\hline $18 \mathrm{~A}$ & $\mathrm{X}$ & 325 & 9,54 & 1,51 & 6,62 \\
\hline \multicolumn{6}{|c|}{ AAA $^{*}=$ argamassa autoadensável } \\
\hline
\end{tabular}

Nota-se, na Figura 9, que as argamassas autoadensáveis responsáveis por referenciarem os concretos autoadensáveis apresentaram valores de área relativa de espalhamento (Gc) no intervalo de 5 a 11,5 e valores de velocidade relativa de fluidez $(\mathrm{Rm})$ no intervalo próximo de $2 \mathrm{~s}^{-1}$ a $7^{-1}$. Esses valores coincidem em parte com os valores encontrados por CHAI [69], o qual sugere valores de área relativa de espalhamento maior e igual a 8 e valores de velocidade relativa de fluidez entre $1 \mathrm{~s}^{-1}$ e $5 \mathrm{~s}^{-1}$. No entanto, os valores encontrados no presente estudo estão fora da região dos valores encontrados por NEPOMUCENO et al. [54], que sugere intervalos bem estreitos, como a área relativa de espalhamento entre 5,30 e 5,90 e velocidade de relativa de fluidez entre $1,14 \mathrm{~s}^{-1}$ e $1,30 \mathrm{~s}^{-1}$.

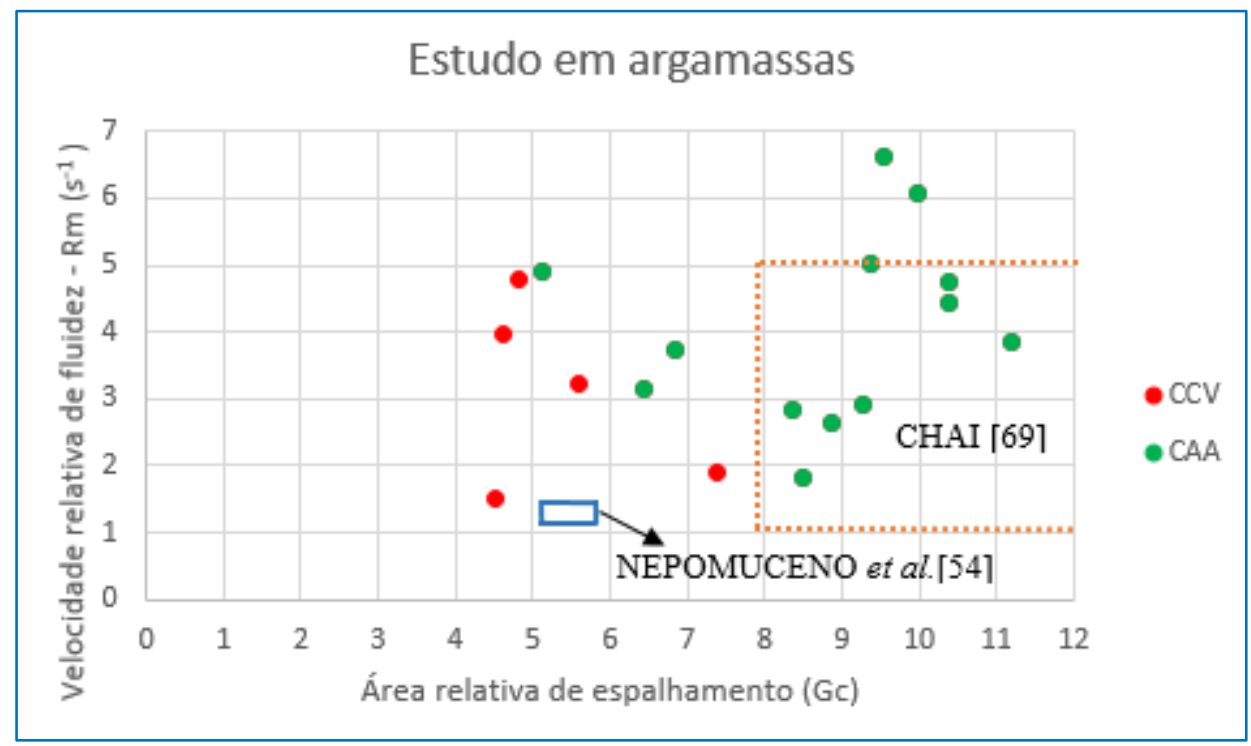

Figura 9: Relação dos resultados de velocidade de deformação-Rm(mini-funil) e capacidade de deformação-Gc das argamassas. 
O fato dos parâmetros de mistura das argamassas autoadensáveis desta tese possuírem valores semelhantes aos valores dos parâmetros de mistura empregados nas argamassas de CHAI [69], pode ser a explicação mais plausível para justificar a coincidência dos valores de autoadensabilidade das argamassas. CHAI [69] adotou, por exemplo, uma relação de volume de areia e volume de argamassa (Vs/Vm) maior que 0,45 para as misturas de relação água/aglomerante superior a 0,34 , portanto corroborando com o valor médio adotado nesta pesquisa que foi 0,48. Entretanto, NEPOMUCENO et al. [54] empregaram a relação Vs/Vm em torno de 0,40; a qual também foi empregada por OUCHI e OKAMURA [1] e considerada por CHAI [69] uma relação muito baixa para um consumo de aglomerante recomendado pelo ACI. Quanto menor a relação de $\mathrm{Vs} / \mathrm{Vm}$, isso implica em um maior emprego de finos na mistura. A relação entre os volumes de finos e de areia $(\mathrm{Vp} / \mathrm{Vs})$ empregada por NEPOMUCENO et al.[54] em suas argamassas autoadensáveis foi entre 0,60 e 0,80 , enquanto que neste trabalho empregou-se um valor em torno de 0,40. Essa diferença entre os valores empregados de $\mathrm{Vp} / \mathrm{Vs}$, pode explicar a disparidade dos valores de autoadensabilidade das argamassas desta pesquisa com os valores de autoadensabilidade das argamassas de NEPOMUCENO et al.[54], conforme estão apresentados na Figura 9.

\subsection{Associação do comportamento de autoadensabilidade das argamassas e dos concretos}

Quanto à capacidade as argamassas referenciarem os concretos autoadensáveis. Tem-se, na Figura 10, a relação dos resultados de espalhamento das argamassas e dos concretos como, também, a relação dos resultados de fluidez (Funil V x mini-funil V). A relação dos resultados de espalhamento, obteve-se uma regressão linear com equação de regressão e coeficiente de determinação que foi igual a 0,81 , conforme está apresentada na Figura 10(a). Observa-se que o espalhamento das argamassas entre $320 \mathrm{~mm}$ e $350 \mathrm{~mm}$ pode alcançar concretos de espalhamento entre $600 \mathrm{~mm}$ e $740 \mathrm{~mm}$. Isso demonstra a importância do ensaio de mini-slump em argamassas para estimar a habilidade de preenchimento dos concretos.
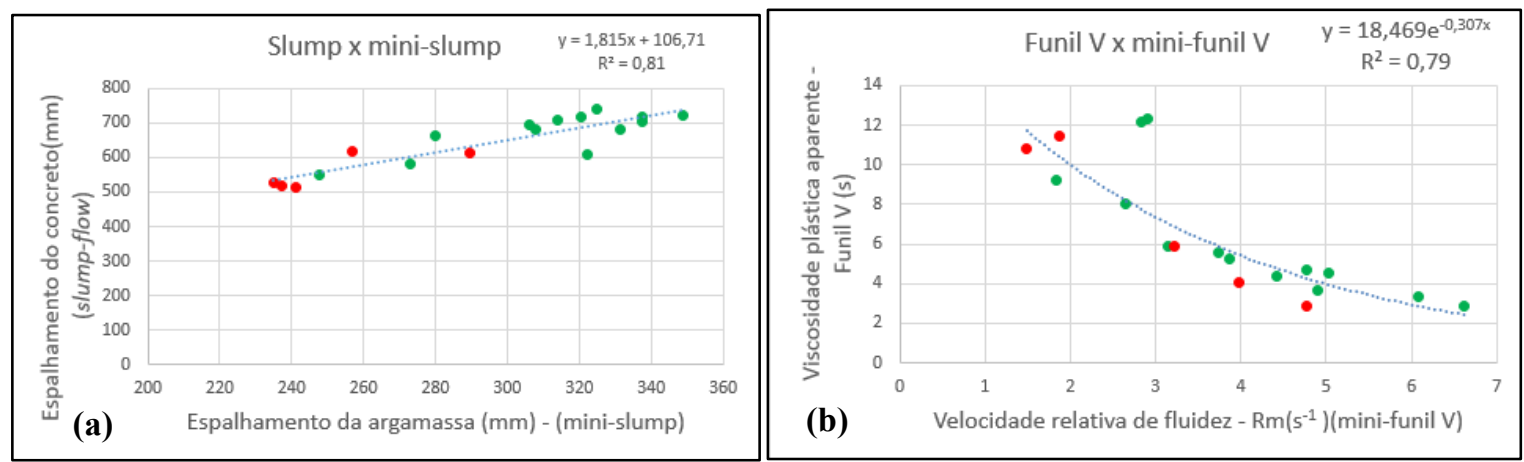

Figura 10: (a) Regressão linear entre os resultados de espalhamento (slump-flow) dos concretos e os resultados de espalhamento (mini-slump) das argamassas. (b) Regressão tipo exponencial entre os resultados dos concretos por meio do ensaio de funil $\mathrm{V}$ e das argamassas referencias por meio do ensaio de mini-funil.

Obteve-se, também, uma relação importante entre os ensaios de mini-funil V e funil V conforme está apresentada na Figura 10 (b). Nesse caso, foi obtida uma regressão tipo exponencial, na qual consta a equação de regressão e o coeficiente de determinação que foi igual a 0,79 . Isso comprova que o ensaio de minifunil V, em argamassas, é importante no sentido de prever a viscosidade plástica aparente e habilidade de preenchimento do concreto.

Diante dos resultados expostos neste item, observou-se que existe uma forte relação das características no estado fresco das argamassas e dos concretos. Isso pode ser explicado pela grande proporção de argamassa em um concreto com proporções compatíveis de um concreto autoadensável. Os concretos produzidos neste estudo tiveram um teor de argamassa de $72 \%$, em volume, portanto um alto teor de argamassa.

\subsection{Comportamento reológico de argamassas e de concretos}

Quanto aos valores dos parâmetros reológicos dos materiais cimentícios estudados neste trabalho, têm-se na Tabela 13, os valores dos parâmetros reológicos das argamassas e, na Tabela 14, os valores dos parâmetros reológicos dos concretos. 
Tabela 13: Resultados dos parâmetros reológicos das argamassas referências mensurados por meio de um reômetro coaxial da marca Rheotest RN 4.1.

\begin{tabular}{|c|c|c|c|}
\hline \multicolumn{4}{|c|}{ Argamassas } \\
\hline Referência & AAA $^{*}$ & $\begin{array}{l}\text { Tensão de } \\
\text { escoamento } \\
\text { (mN.m.min) }\end{array}$ & $\begin{array}{c}\text { Viscosidade } \\
\text { Plástica de torque } \\
\text { (mN.m.min) }\end{array}$ \\
\hline $1 \mathrm{~A}$ & & 26,27 & 1,77 \\
\hline $2 \mathrm{~A}$ & $\mathrm{X}$ & 12,23 & 1,17 \\
\hline $3 \mathrm{~A}$ & & 10,91 & 1,24 \\
\hline $4 \mathrm{~A}$ & $\mathrm{X}$ & 22,59 & 1,60 \\
\hline $5 \mathrm{~A}$ & $\mathrm{X}$ & 17,44 & 0,95 \\
\hline $6 \mathrm{~A}$ & $\mathrm{X}$ & 21,80 & 1,60 \\
\hline $7 \mathrm{~A}$ & $X$ & 12,29 & 0,79 \\
\hline $8 \mathrm{~A}$ & $\mathrm{X}$ & 39,56 & 0,62 \\
\hline $9 \mathrm{~A}$ & & 12,90 & 0,56 \\
\hline $10 \mathrm{~A}$ & $\mathrm{X}$ & 27,60 & 0,90 \\
\hline $11 \mathrm{~A}$ & $\mathrm{X}$ & 13,47 & 0,72 \\
\hline $12 \mathrm{~A}$ & $\mathrm{X}$ & 8,59 & 0,43 \\
\hline $13 \mathrm{~A}$ & & 15,75 & 0,53 \\
\hline $14 \mathrm{~A}$ & $\mathrm{X}$ & 8,55 & 0,32 \\
\hline $15 \mathrm{~A}$ & $X$ & 18,27 & 0,46 \\
\hline $16 \mathrm{~A}$ & $\mathrm{X}$ & 24,07 & 0,28 \\
\hline $17 \mathrm{~A}$ & & 6,20 & 0,34 \\
\hline $18 \mathrm{~A}$ & $\mathrm{X}$ & 13,67 & 0,25 \\
\hline
\end{tabular}

Tabela 14: Resultados dos parâmetros reológicos dos concretos estimados por meio das equações propostas de SEDRAN e De LARRARD [19].

\begin{tabular}{|c|c|c|c|}
\hline \multicolumn{4}{|c|}{ Concretos } \\
\hline Referência & CAA $^{*}$ & $\begin{array}{l}\text { Tensão de escoamento teórico } \\
(\mathrm{Pa})\end{array}$ & Viscosidade plastica (Pa.s) \\
\hline $1 \mathrm{C}$ & & 542,77 & 111,81 \\
\hline $2 \mathrm{C}$ & $\mathrm{X}$ & 252,29 & 187,17 \\
\hline $3 \mathrm{C}$ & & 378,75 & 130,97 \\
\hline $4 \mathrm{C}$ & $\mathrm{X}$ & 181,95 & 116,79 \\
\hline $5 \mathrm{C}$ & $\mathrm{X}$ & 222,69 & 147,14 \\
\hline $6 \mathrm{C}$ & $\mathrm{X}$ & 196,37 & 86,51 \\
\hline $7 \mathrm{C}$ & $\mathrm{X}$ & 440,22 & 67,31 \\
\hline $8 \mathrm{C}$ & $\mathrm{X}$ & 167,74 & 122,72 \\
\hline $9 \mathrm{C}$ & & 269,55 & 81,50 \\
\hline $10 \mathrm{C}$ & $\mathrm{X}$ & 173,21 & 120,38 \\
\hline $11 \mathrm{C}$ & $\mathrm{X}$ & 280,04 & 79,13 \\
\hline $12 \mathrm{C}$ & $\mathrm{X}$ & 204,15 & 61,61 \\
\hline $13 \mathrm{C}$ & & 549,32 & 70,28 \\
\hline $14 \mathrm{C}$ & $\mathrm{X}$ & 388,18 & 114,26 \\
\hline $15 \mathrm{C}$ & $\mathrm{X}$ & 497,84 & 46,41 \\
\hline $16 \mathrm{C}$ & $\mathrm{X}$ & 244,45 & 49,51 \\
\hline $17 \mathrm{C}$ & & 580,07 & 65,27 \\
\hline $18 \mathrm{C}$ & $\mathrm{X}$ & 133,84 & 70,48 \\
\hline
\end{tabular}

Com esses resultados dos parâmetros reológicos das argamassas e dos concretos, buscou-se identificar alguma relação entre esses parâmetros, assim como relacioná-los com parâmetros de viscosidade aparente ou fluidez desses materiais. Primeiro, tem-se na Figura 11, a relação dos resultados de viscosidade plástica de torque com resultados de velocidade de deformação (mini-funil) das argamassas referencias. Observa-se uma regressão tipo exponencial, na qual consta uma equação com coeficiente de determinação igual a 0,78 . Notase que os parâmetros de velocidade de deformação e viscosidade plástica de torque são grandezas que tendem ser inversas, ou seja, argamassas com baixas velocidades de deformação possuem maiores valores de viscosidade plástica de torque. No geral, na Figura 11, verifica-se que os valores de viscosidade plástica de torque das argamassas referencias de concretos autoadensáveis estão compreendidos no intervalo de $0,25 \mathrm{mN}$.m.min a 1,60 mN.m.min. 


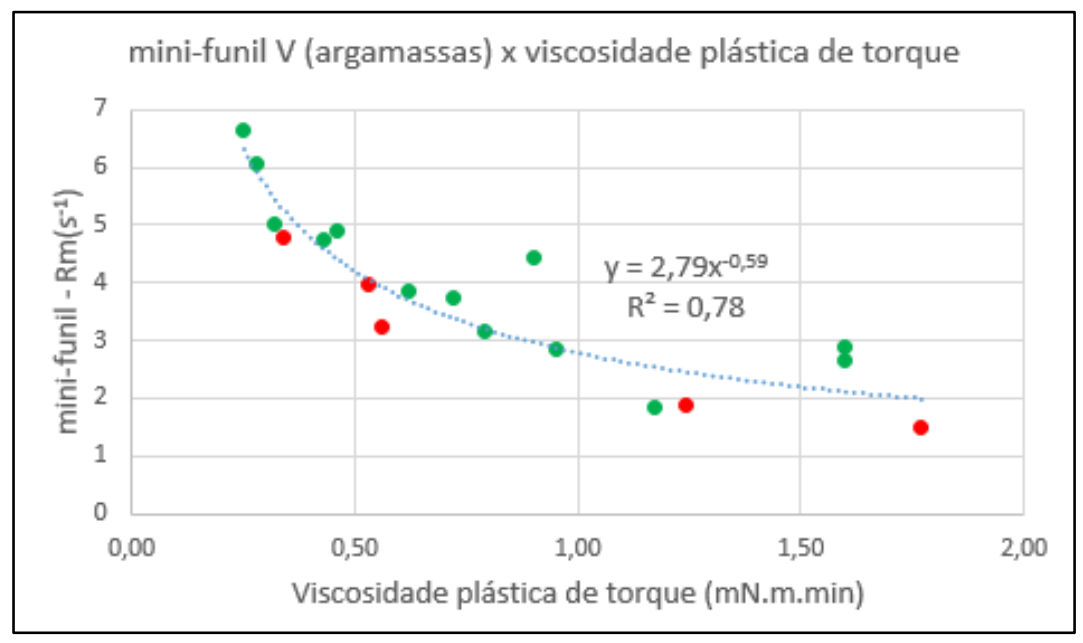

Figura 11: Regressão tipo exponencial entre os resultados de velocidade de deformação-Rm e os resultados de viscosidade plástica de torque das argamassas.

Em seguida, na Figura 12, têm-se as relações dos valores de viscosidade plástica de torque das argamassas referências com os valores de viscosidade plástica aparente dos concretos obtidos por meio dos ensaios de funil V e de T500, respectivamente. Observa-se, na Figura 12(a), que a relação entre os resultados de viscosidade plástica aparente pelo ensaio de funil $\mathrm{V}$ e viscosidade plástica de torque, conferiu-se uma regressão linear com uma equação de coeficiente de determinação igual a 0,71 ; portanto uma relação importante que demonstra uma tendência bem definida. No entanto, na Figura 12(b), os resultados de viscosidade plástica aparente, obtidos por meio do ensaio de T500, quando relacionados com os resultados de viscosidade plástica de torque não se obteve uma regressão linear relevante, visto que o coeficiente de determinação foi igual a 0,31 . Isso significa, mais uma vez, que os valores gerados pelo ensaio de T500 não têm o mesmo grau de confiabilidade dos valores gerados pelo ensaio de funil $\mathrm{V}$, portanto deve-se avaliar a capacidade do ensaio T500 em definir o quesito de habilidade de preenchimento ou viscosidade do concreto.
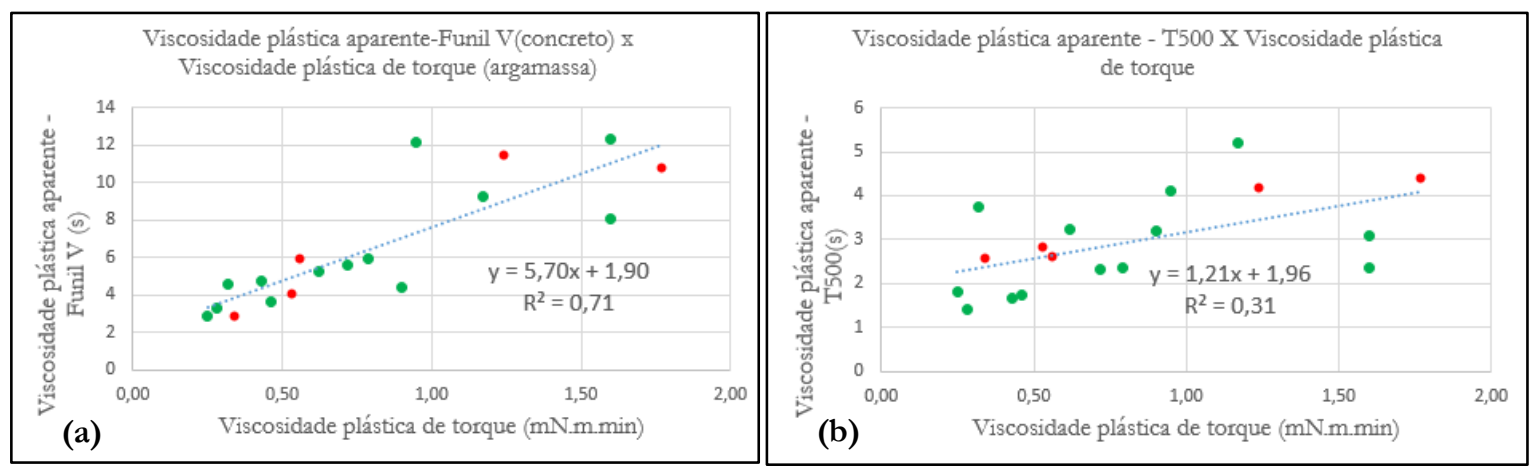

Figura 12: (a) Regressão tipo linear entre os resultados de viscosidade plástica aparente dos concretos por meio do ensaio de funil V e resultados de viscosidade plástica de torque das argamassas. (b) Regressão tipo linear entre os resultados de viscosidade plástica aparente dos concretos por meio do ensaio T500 e resultados de viscosidade plástica de torque das argamassas.

Com relação os parâmetros reológicos do concreto, decidiu-se adotar os modelos matemáticos de SEDRAN e DE LARRARD [19] para estimar esses parâmetros, conforme está relatado na seção 2 deste trabalho. Para tanto, os resultados estimados dos parâmetros reológicos estão apresentados na Tabela 12 e Figura 13. 


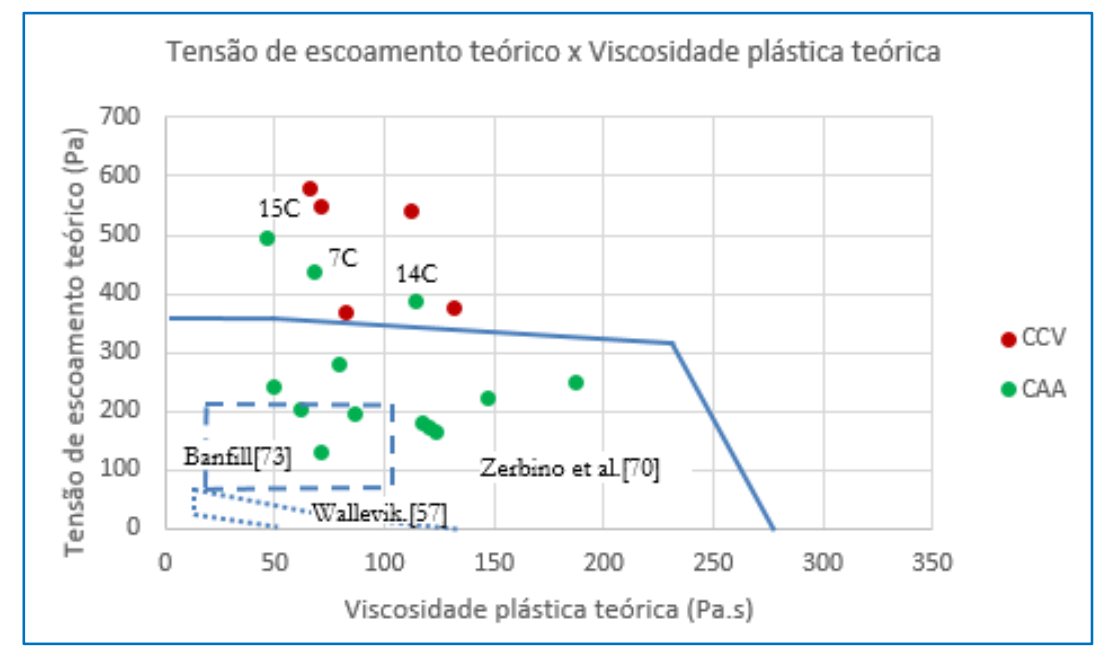

Figura 13: Relação dos resultados de tensão de escoamento teórico e viscosidade plástica teórica dos concretos.

Nota-se, na Figura 13, que boa parte dos concretos classificados como autoadensável apresentou valores dos parâmetros reológicos no domínio recomendado por ZERBINO et al.[70], enquanto três concretos autoadensáveis ficaram fora desse domínio. No entanto, quando se considera o erro médio de 95Pa para previsão da tensão escoamento proposta pela equação de SEDRAN e DE LARRARD [19], pode-se afirmar que somente um concreto autoadensável (concreto de $\mathrm{n}^{\circ} 15 \mathrm{C}$ ) ficaria fora do domínio de ZERBINO et al. [70].

Outros pesquisadores, tais como, PETIT et al. [71] e HEIRMAN et al. [72], também, encontraram valores dos parâmetros reológicos dos concretos autoadensáveis nesse domínio.

Além disso, verifica-se, na Figura 13, que somente três concretos autoadensáveis apresentaram valores de parâmetros reológicos no domínio recomendado por BANFILL [73] e nenhum concreto apresentou valor no domínio recomendado por WALLEVIK [57]. Por fim, constata-se, no presente trabalho, que os valores estimados dos parâmetros reológicos dos concretos autoadensáveis são correlatos aos valores já encontrados por outros pesquisadores.

\section{CONCLUSÕES}

A seguir, as principais conclusões obtidas nesse trabalho:

- No geral, observou-se que definir autoadensabilidade do concreto não transparece algo simples e resolvido no ponta de vista técnico e científico. Notou-se a falta de concordância entre ensaios que avaliam o mesmo quesito de autoadensabilidade, bem como foi possível classificar um concreto como autoadensável sem cumprir com o quesito de resistência à segregação;

- Quanto a estabilidade do concreto, observou-se que os concretos 16C e 18C apresentaram resultados iguais a $21,31 \%$ e $34,26 \%$, respectivamente. Isso significa, que esses concretos segregaram conforme definido pela ABNT NBR 15823-1 [30]. Entretanto, quando se faz uma avaliação por inspeção visual do estado fresco desses concretos, nota-se na Figura 8(a), que o concreto 16C é um concreto coeso, ao contrário, do concreto 18C, Figura 8(b), que apresenta ser um concreto que realmente segregou e exsudou. Diante disso, constata-se que a inspeção visual ainda é um instrumento importante para avaliar a estabilidade de qualquer material cimentício no estado fresco, assim como desperta-se o questionamento frente o ensaio de coluna de segregação no que tange sua capacidade de classificar a estabilidade do concreto;

- Pode-se afirmar que os estudos em argamassas foram capazes de referenciar os prováveis concretos autoadensáveis. Isso pode ser explicado pela grande proporção de argamassa na composição do concreto. Os concretos produzidos neste estudo tiveram um teor de argamassa de $72 \%$, em volume, portanto um alto teor de argamassa típico de um concreto autoadensável;

- Foi possível obter uma regressão tipo linear entre os resultados de espalhamento das argamassas por meio do ensaio de mini-slump e os resultados de espalhamento dos concretos por meio do ensaio de slump flow dos concretos; 
- Foi possível, também, obter uma tendência entre os resultados do ensaio de funil $\mathrm{V}$ dos concretos e os resultados do ensaio de mini-funil V das argamassas. Nesse caso, obteve-se uma regressão tipo exponencial.

- Foi efetuada uma relação dos resultados de viscosidade plástica aparente gerados pelos ensaios de Funil V e de T500, na qual obteve-se uma regressão linear com coeficiente de determinação igual a 0,46. Diante disso, constatou-se que a relação não é boa, portanto sugere-se um cuidado maior na avaliação desse quesito para a classificação da autoadensabilidade do concreto;

- Não foi obtida uma importante relação dos resultados de viscosidade plástica aparente dos concretos, gerados por meio do ensaio T500, com os resultados de viscosidade plástica de torque das argamassas. Entretanto, obteve-se uma boa relação dos resultados de viscosidade plástica dos concretos gerados por meio do ensaio de funil V com os resultados de viscosidade de torque das argamassas. Dessa forma, constatou-se que os valores de viscosidade plástica aparente obtidos pelo ensaio de funil V são mais confiáveis do que os valores de viscosidade plástica aparente obtidos pelo ensaio T500;

- Com relação a avaliação da habilidade passante, notou-se que somente dez concretos foram classificados tanto pelo ensaio de anel J como, também, pelo ensaio de caixa L. Isso significa que não há uma relação importante entre os ensaios que avaliam habilidade passante. Além disso, observou-se que o quesito habilidade passante demonstrou ser determinante para classificar o concreto em autoadensável. Pode-se citar o exemplo dos cinco concretos que não foram classificados como autoadensável, dos quais três concretos não cumpriram com esse quesito. Cabe frisar, também, que o anel J adotado pela norma brasileira é menos rigoroso na avaliação da habilidade passante do concreto pelo fato de possuir barras verticais com diâmetros iguais a $(10 \pm 3,0) \mathrm{mm}$, portanto esta medida de diâmetro é inferior dos anéis J prescritos por normas europeias e pela norma americana que possuem diâmetros iguais a $(18 \pm 0,5) \mathrm{mm}$ e $(16 \pm 3,3) \mathrm{mm}$, respectivamente;

- Os resultados de espalhamento do concreto apresentaram uma boa relação com os resultados dos ensaios de caixa L e de caixa U. Diante disso, pode-se dizer que é possível estimar habilidade passante dos concretos por meio do ensaio de espalhamento (slump flow);

- Com base nos resultados do ensaio de caixa U, sugere-se dois níveis de classificação de autoadensabilidade, sendo um nível de resultados em um intervalo de $0 \mathrm{~mm}$ até $30 \mathrm{~mm}$ e outro nível para resultados maiores que $30 \mathrm{~mm}$ até $60 \mathrm{~mm}$. Essa sugestão é importante para uma futura inclusão desse ensaio em normas vigentes. LIBRE et al [66] detectaram que o ensaio de caixa $U$ foi mais eficiente do que o ensaio de caixa $\mathrm{L}$ para detectar alterações na composição do concreto;

- Os parâmetros reológicos teóricos dos concretos autoadensáveis, estimados pelas equações de SEDRAN e DE LARRARD [19], apresentaram valores dentro dos domínios propostos pelos pesquisadores que estudaram e estudam a tecnologia do concreto autoadensável.

\section{AGRADECIMENTOS}

Agradecemos o apoio das empresas que forneceram os materiais empregados nesta pesquisa, as quais são: Ciplan Cimentos-DF, Ciplan Concreteira-DF, Pedreira Pioneira - Formosa-Go e Grace Aditivos. Agradecemos o apoio da equipe técnica e da infraestrutura do Lem-UnB, bem como a equipe da UFBA que nos auxiliou na caracterização reológica das argamassas.

\section{BIBLIOGRAFIA}

[1] OKAMURA, H., OUCHI, M., "Self-compacting concrete", Journal of Advanced Concrete Technology, v. 1, n. 1, pp. 5-15, 2003.

[2] ATTIOGBE, E., SEE H., DACZKO, J., "Engineering properties of self-consolidating concrete", In: Proceedings of the First North American conference on the design and use of self-compacting concrete, Nov. 2002.

[3] BILLBERG, P, "Development of SCC static yield stress at rest and its effect on the lateral form pressure", In: SCC 2005, combining the second North American conference on the design and use of selfconsolidating concrete and the fourth international RILEM symposium on self-compacting concrete, pp.583589, 2005.

[4] MARTYS, N., FERRARIS C., "Simulation of SCC flow", In: Proc. $1^{\text {st }}$ North American Conf. on the design and use of Self-Consolidating Concrete, pp.27-30, Chicago, 2002. 
[5] KLUG, Y.; HOLSHEMACHER, K., "Comparison of the hardened properties of self-compacting and normal vibrated concrete", In: Proceedings of the $3^{\text {rd }}$ RILEM symposium on self-compacting concrete, pp.596-605, Reykjavik, 2003.

[6] FAVA, C., BERGOL, L., FORNASIER, G., GIANGRASSO, F., ROCCO, C., "Fracture behavior of selfcompacting concrete", In: Proceedings of the $3^{\text {rd }}$ RILEM symposium on self-compacting concrete, pp. 628636, Reykjavik, 2003.

[7] WALLEVIK, O., KUBENS S., MÜLLER F., "Influence of cement-admixture interaction on the stability of production properties of SCC", In: Proceedings of the $5^{\text {th }}$ International RILEM symposium on selfcompacting concrete, RILEM Publications SARL, p.211-216, 2007.

[8] NUNES, S., COUTINHO, J. S., FARIA, R., editores, Livro de comunicações do IV Congresso Iberoamericano sobre Betão Auto-compactável - BAC2015, FEUP, pp.1-628, Porto, 2015.

[9] SHI, C., WU, Z., LV, K., WU, L., "A review on mixture design methods for self-compacting concrete", Construction and Building Materials, v.84, pp.387-398, 2015.

[10] OKAMURA, H., OZAWA, K, "Mix design for self-compacting concrete", Concrete Library if Japonese Society of Civil Engineers, v.25, n.6, pp-107-120, 1995.

[11] EDAMATSU, Y., NISHIDA N., OUCHI, M., "A rational mix-design method for self-compacting concrete considering interaction between coarse aggregate and mortar particles", In: Proceedings of the first international RILEM symposium on self-compacting concrete, Stockholm, pp.309-320, 1999.

[12] DOMONE, P, Proportioning of self-compacting concrete - the UCL method, Department of Civil, Environmental and Geomatic Engineering, University College, London, pp.1-30, 2009.

[13] KHALEEL, O., ABDUL R., "Mix design method for self-compacting metakaolin concrete with different properties of coarse aggregate", Materials Design, v. 53, p 691-700, 2014.

[14] GHAZI, F., RAND, S. A. J., "New method for proportioning self-consolidating concrete based on compressive strength requirements", ACI Materials Journal, pp. 490-497, Sept. 2010.

[15] DINAKAR, P., SETHY, K., SAHOO, U., "Design of self-compacting concrete with ground granulated blast furnace slag", Materials Design, v.43, pp. 161-169, 2013.

[16] HWANG, C., TSAI, C., "The effect of aggregate packing types on engineering properties of selfconsolidating concrete" In: Zhiwu Yu et al., editors, SCC 2005- China: $1^{\text {st }}$ international symposium on design, performance and use of self-consolidating concrete. RILEM Publications SARL, 2005.

[17] PETERSSON, O., BILLBERG, P., VAN, B., A model for self-compacting concrete, [s.1], 1996.

[18] SU, N., HSU, K., CHAI, H., "A simple mix design method for self-compacting concrete", Cement Concrete Research, v.31, pp.1799-1807, 2001.

[19] SEDRAN, T., De LARRARD, F., "Optimization of self-compacting concrete thanks to packing model, In: Proceedings $1^{\text {st }}$ SCC Symp, CBI, RILEM PRO7, Suécia, 1999.

[20] SHI, C., et al, "Design and application of self-compacting lightweight concrete", In: SCC2005-China: $I^{\text {st }}$ international symposium on design, performance and use of self-consolidating concrete. RILEM Publications SARL, 2005.

[21] SEBAIBI, N., BENZERZOUR, M., SEBAIBI, Y., et al., "Composition of self -compacting concrete using the compressible packing model, the Chinese method and the European standard", Construction and Building Materials, v.43, p.382-388, 2013.

[22] KANADASAN, J., RAZAK, H., "Mix design for self-compacting palm oil clinker concrete based on particle packing", Materials Design, v.56, pp. 9-19, 2014.

[23] KHAYAT, K., GHEZAL, A., HADRICHE, M., "Factorial design model for proportioning selfconsolidating concrete", Materials Structures, v.33, pp.338-344, 2000.

[24] OZBAY, E., OZTAS, A., BAYKASOGLU, A., et al., "Investigating mix proportions of high strength self-compacting concrete by using Taguchi method", Construction and Building Materials, v.23, p.694-702, 2009.

[25] BOUZIANI, T, "Assessment of fresh properties and compressive strength of self-compacting concrete made with different sand types by mixture design modelling approach", Construction and Building Materials, v.49, p.308-314, 2013.

[26] SAAK, A., JENNINGS, H., SHAH, S., "New methodology for designing self-compacting concrete", ACI Materials Journal, v.98, n.6, pp. 429-439, 2001. 
[27] BUI, V., AKKAYA, Y., SHAH, S., "Rheological model for self-consolidating concrete", ACI Materials Journal, v.99, pp. 549-559, 2002.

[28] FERRARA, L., PARK, Y., SHAH, S., “A method for mix-design of fiber reinforced self-compacting concrete", Cement Concrete Research, v.37, pp.957-971, 2007.

[29] JIN, J., Properties of mortar for self-compacting concrete,.Tese de D.Sc., Department of Civil and Environmental Engineering, Universidade of London, London, 2002.

[30] ASSOCIAÇÃO BRASILEIRA DE NORMAS TECNICAS. NBR 15823-1: Concreto Autoadensável: Classificação, controle e aceitação no estado fresco. Rio de Janeiro, 2010.

[31] JACOBS, H., Design of SCC for durable concrete structures, 1999.

[32] GOMES, P.C.C. Optimization and characterization of high-strength self-compacting concrete, Tese de D. Sc - Universitat Politécnica de Catalunya, Barcelona, Espanha, 139p, 2002.

[33] LACHEMI, M., HOSSAIN, K. M. A., PATEL, R., et al., "Influence of paste/mortar rheology on the flow characteristics of high-volume fly ash self-consolidating concrete", In: Magazine of Concrete Research, n.59, p. 517-528, 2007.

[34] LIU, M., Wider Application of Additions in Self-Compacting Concrete, 367p., Tese de D. Sc, Departament of Civil, Environmental and Geomatic Engineering, University College London, Londres, 2009.

[35] FUNG, W. W. Role of water film thickness in rheology of mortar and concrete., Tese de D. Sc. - Universidade de Hong Kong, Hong Kong, 2010.

[36] JIN, J., DOMONE, P. L. J, "Relationships between the fresh properties of SCC and its mortar componente" In: SKARENDAHL, A.(Ed.), The 1st North American Conference on the design and use of selfconsolidating concrete, pp. 33 - 38, Chicago, 2002.

[37] ROY, R. L., ROUSSEL, N., "The Marsh cone as a viscometer: Theoretical analysis and practical limits”, Materials and Structures, n.38, pp.25-30, 2005.

[38] SCHWARTZENTRUBER, L. D., ROY, R. L., CORDIN, J, "Rheological behaviour of fresh cement pastes formulated from a Self-Compacting Concrete (SCC)”, Cement and Concrete Research, n.36, pp.1203$1213,2006$.

[39] EL-CHABIB, H., NEHDI, M., "Effect of mix design parameters on segregation of self-consolidating concrete”, ACI Materials Journal, v.103, pp. 393 - 398, 2006.

[40] OZAWA, K., SAKATA, N., OKAMURA, H., "Evaluation of self-compatibility of fresh concrete using the funnel test", In: Proc. of the Japan Society of Civil Engineers, vol. 23, n. 490, p. 71-80, 1994.

[41] GROTH, P., NEMEGEER, D., "The use of steel fibres in self-compacting concrete", In: SKARENDAHL, A., PETERSSON, Ö. (ed), Proc. 1st International RILEM Symposium on Self-Compacting Concrete, RILEM Publications S.A.R.L, Stockholm, Sweden, p. 497-508, 1999.

[42] PETERSSON, Ö., BILLBERG, P., VAN, B. K, “A model for self-compacting concrete”, In: BARTOS, P. J. M., MARRS, D. L., CLEAND, D. J.(eds), In: Proc. International RILEM Conference on Production Methods and Workability of Concrete, E \& FN, pp. 483-492, 1996.

[43] EFNARC, Specification and Guidelines for Self-Compacting Concrete, Ucrânia, 2005.

[44] ASSOCIAÇÃO BRASILEIRA DE NORMAS TECNICAS. NBR 15823-2: Concreto Autoadensável: Determinação do espalhamento e do tempo de escoamento - Método do cone de Abrams. Rio de Janeiro, 2010.

[45] ASTMC1610/C 1610 M-10: Standard test method for static segregation of self-consolidating concrete using column technique, ASTM International, 2010.

[46] ROONEY, M., J., BARTOS, P., J., M., “Development of the settlement column segregation test for fresh self-compacting concrete, In: Proceedings of the Second International Symposium on Self-Compacting Concrete, Coms Engineering Corp, Tokyo, pp 109-116, 2001.

[47] BUI, V., K., MONTGOMERY, D., HINCZAK, I., et al., "Rapid testing method for segregation resistance of self-compacting concrete", Cement Concrete Research, v.32, p.1489-1496, 2002.

[48] ILLINOIS TEST PROCEDURE SCC-7: Standard test method for static segregation of fresh selfconsolidating concrete cylinders using the static segregation probe, FHWA-ICT- 08-020, 2008.

[49] ILLINOIS TEST PROCEDURE SCC-8: Standard test method for assessment of dynamic segregation of self-consolidating concrete during placement, FHWA-ICT-08-020, 2008. 
[50] CUSSIGH, F., et al., "Project testing SCC-segregation test methods", In: Wallevik O, Nielsson I (eds) Self-compacting concrete, Third international RILEM symposium on self-compacting concrete, Reykjavik. RILEM Publications SARL, Bagneux, p 311, 2003.

[51] HU, C., LARRARD F., SEDRAN, T., et al., "Validation of BTRHEOM, the new rheometer for soft-to fluid concrete", Materials Structures, v. 29, pp. 620-631, 1996.

[52] OPERATING MANUAL THE BML VISCOMETER, The viscometer 4, Con Tec, 2000.

[53] TATERSALL, G., H, BLOOMER, S., J., "Further development of the two-point test for workability and extension of its range", Magazine Concrete Research, v. 31, p. 202-210, 1979.

[54] NEPOMUCENO, M., C., S., OLIVEIRA, L. A., LOPES, S., "Methodology for the mix design of selfcompacting concrete using different mineral additions in binary blends of powders", Construction and Building Materials, v.64, pp.82-94, 2014.

[55] ROUSSEL, N., STEFANI, C., LE ROY, R., "From mini cone test to Abrams cone test: measurement of cement based materials yield stress using slump tests", Cement Concrete Research, v. 35, pp. 817-822, 2005.

[56] NGUYEN, T. L. H., ROUSSEL, N., COUSSOT, P., "Correlation between L-box test and rheological parameters of homogeneous yield stress fluid", Cement Concrete Research, v. 36, pp. 1789-1796, 2006.

[57] WALLEVIK, J. E., "Relationship between the Bingham parameters and slump", Cement and Concrete Research, n.36, pp. 1214 - 1221, 2006.

[58] WALLEVIK, O. H., WALLEVIK, J. E. "Rheology as a tool in concrete science: The use of rheographs and workability boxes", Cement and Concrete Research, n.41, pp. 1279 - 1288, 2011.

[59] KWAN, A. K. H, WONG, H. H. C., "Effects of packing density, excess water and solid surface area on flowability of cement paste", Advances in Cement Research, v.20, pp. 1-11, 2008.

[60] KWAN, A. K. H., FUNG, W. W. S., WONG, H. H. C. "Water film thickness, flowability and rheology of cement - sand mortar", Advances in Cement Research, v. 22, pp. 3-14, 2010.

[61] KWAN, A. K. H., LI, L. G., "Combined effects of water film, paste film and mortar film thickness on fresh properties of concrete", Advances in Cement Research, v. 22, p. 3-14, 2010.

[62] MENDES, M. V. A. S., BAUER, E, "Avaliação da capacidade do parâmetro wft (water film thickness) contribuir para a obtenção do concreto autoadensável”, In: IV Congresso Ibero-americano sobre Betão Autocompactável - BAC2015 - FEUP, Anais, Porto, Portugal, pp. 277-287, 2015.

[63] TANIGAWA, Y., MORI, H., "Analytical study on deformation of fresh concrete", Journal of Engineering Mechanics, v.115, p.493-508, 1989.

[64] ASSOCIAÇÃO BRASILEIRA DE NORMAS TÉCNICAS. NBR NM 248: Agregados Determinação da Composição Granulométrica. Rio de Janeiro, 2003.

[65] AMERICAN CONCRETE INSTITUTE. ACI 237R-07: Self-Consolidating Concrete, 2007.

[66] LIBRE, N. A., KHOSHNAZAR, R., MOHAMMAD, S., "Repeatability, responsiveness and relative cost analysis of SCC workability test methods", Materials and Structures, n.45, p. 1087-1100, 2012.

[67] SAHMARAN, M., CHRISTIANTO, H., YAMAN, I. O., "The effect of chemical admixtures and mineral additives on the properties of self-compacting mortars", Cement Concrete Research, n.28, pp. 432-440, 2006.

[68] TÜRKEL, S., KANDEMIR, A, "Fresh and hardened properties of SCC made with different aggregate and mineral admixtures, Jornal of Materials in Civil Engineering, n.10, pp. 1025 - 1031, 2010.

[69] CHAI, H. Design and Testing of Self-Compacting. Tese D.Sc., Departament of Civil, Environmental, University College London, Londres, 1998.

[70] ZERBINO, R., BARRAGAN, B., GARCIA, T., et al., "Workability tests and rheological parameters in self-compacting concrete", Materials Structures, v. 42, pp. 947-960, 2009.

[71] PETIT, J. K., WIRQUIN, E., VANHOVE, Y., et al., "Yield stress and viscosity equations for mortars and self-consolidating concrete", Cement Concrete Research, v. 37, pp. 655-670, 2007.

[72] HEIRMAN, G., HENDRICKX, R., VANDEWALLE, L., et al, "Integration approach of the Couette inverse problem of powder type sel-compacting concrete in a wipe-gap concentric cylinder rheometer Part II. Influence of mineral addition and chemical admixtures on the shear thickening flow behavior", Cement Concrete Research, v. 39, pp. 171-181, 2006.

[73] BANFILL, P. F. G, "Rheology of fresh cement and concrete", Rheology reviews, pp.61-130, 2006. 